$\triangle N E<$ LABORATÓRIO NACIONAL

DE ENGENHARIA CIVIL

DEPARTAMENTO DE HIDRÁULICA E AMBIENTE

Núcleo de Estuários e Zonas Costeiras

Proc. 0604/011/17744

\title{
EROSÃO DE DUNAS COM OS MODELOS XBEACH E LITPROF
}

Lisboa • Dezembro de 2011

I\&D HIDRÁULICA E AMBIENTE 



\section{EROSÃO DE DUNAS COM OS MODELOS XBEACH E}

LITPROF

\section{DUNE EROSION WITH THE XBEACH AND LITPROF MODELS}

ÉROSION DES DUNES AVEC LES MODĖLES XBEACH ET

LITPROF 


\section{EROSÃO DE DUNAS COM OS MODELOS \\ XBEACH E LITPROF}

\section{RESUMO}

Este estudo enquadra-se na área da investigação científica da dinâmica litoral e visa melhorar a avaliação e previsão da vulnerabilidade/resiliência de sistemas dunares à acção das ondas em condições de tempestade marítima. $O$ objectivo do estudo foi avaliar o desempenho dos modelos XBeach (com elevado potencial para erosão de praias e dunas) e Litprof do sistema de modelação Litpack (um dos modelos mais eficazes nesta área, vastamente aplicado a nível mundial em projectos de investigação e consultoria) na erosão de dunas. Testaram-se os modelos para um caso de verificação de erosão de duna realizado em canal de grande escala de laboratório. A avaliação do desempenho dos modelos foi feita com base na análise da evolução morfológica e em indicadores de impacto (volume de erosão, recuo da duna e recuo do topo da duna) e de erro (Brier Skill Score). Apresentam-se e testam-se os parâmetros por defeito (standard set of parameter settings) para ambos os modelos. Da avaliação de desempenho dos dois modelos com os parâmetros por defeito concluiu-se que o desempenho do modelo XBeach é razoável e do modelo Litprof é fraco. Recomenda-se que numa aplicação de engenharia para previsão da erosão de dunas, em que importa não só a precisão como também estar do lado da segurança, o modelo XBeach com os parâmetros por defeito deve ser usado com precaução, uma vez que 0 volume de erosão foi subestimado. Apresentam-se, discutem-se e testam-se os parâmetros de calibração para ambos os modelos. Concluiu-se que os parâmetros mais influentes na evolução morfológica foram: beta, break, facua, gammax, hswitch, Iws e wets/p, para o modelo XBeach e Maximum Angle of Bed Slope, para o modelo Litprof. Os parâmetros Iws e wets/p do modelo XBeach foram aqueles que conferiram ao perfil final uma geometria mais próxima da configuração observada. Os resultados obtidos para o indicador de erro BSS evidenciam que o melhor desempenho foi obtido com alteração do parâmetro Iws e que o segundo melhor desempenho foi obtido com a alteração do parâmetro wets/p, sendo a ambos atribuída a classificação de excelente. Uma vez que a alteração morfológica alcançada com a modificação do parâmetro Iws permitiu melhorar a previsão das duas características fundamentais sob o ponto de vista da engenharia que são o recuo do topo da duna e 0 limite da extensão da zona activa (onde se observou a formação da barra submersa durante a experiência), considera-se que este parâmetro é de grande relevância na simulação da evolução da erosão de dunas com o modelo XBeach. No seu melhor desempenho o modelo Litprof calibrado reproduziu correctamente o recuo do topo da duna, simulou a formação de uma barra submersa na posição observada experimentalmente, simulou incorrectamente o volume de erosão (cerca de metade do observado) e o declive da duna, e consequentemente gerou um avanço da duna ao nível do mar em vez de recuo. Por este motivo recomenda-se precaução na aplicação do modelo Litprof para previsão da erosão de dunas. Verificou-se também que a teoria de onda não foi relevante na evolução do perfil neste caso de estudo. Da comparação dos modelos morfodinâmicos XBeach e Litprof nas duas fases, i.e., na fase de teste com os parâmetros por defeito e na fase de calibração, concluiu-se que foi o modelo Xbeach que apresentou o melhor desempenho neste caso de estudo. A execução deste estudo permitiu testar e ficar a conhecer a elevada capacidade do modelo XBeach e a razoável capacidade do modelo Litprof na previsão da erosão de dunas.

Palavras-chave: Erosão Costeira, Duna, Modelação Morfodinâmica, XBeach, Litprof. 


\section{EROSÃO DE DUNAS COM OS MODELOS}

\section{XBEACH E LITPROF}

Índice

$\begin{array}{lr}\text { Índice } & \mathrm{V} \\ \text { Índice de figuras } & \mathrm{VI} \\ \text { Índice de tabelas } & \mathrm{VIII}\end{array}$

$\begin{array}{ll}\text { 1. INTRODUÇÃOO } & 1\end{array}$

1.1 ENQUADRAMENTO, MOTIVAÇÃO E OBJECTIVOS

1.2 ORGANIZAÇÃO DO RELATÓRIO 2

2. ABORDAGEM METODOLÓGICA 3

3. FORMULAÇÃO DO MODELO XBEACH

4. RESULTADOS 10

4.1 CASO DE VERIFICAÇÃO

4.2 AVALIAÇÃO COM PARÂMETROS POR DEFEITO

4.2.1 Modelo XBeach 12

4.2.2 Modelo Litprof 14

4.2.3 Comparação 17

4.3 CALIBRAÇÃO

4.3.1 Modelo XBeach 22

4.3.2 Modelo Litprof 25

4.3.3 Comparação 30

5. SUMÁRIO, CONCLUSÕES E TRABALHO FUTURO 33

6. REFERÊNCIAS $\quad 35$ 


\section{EROSÃO DE DUNAS COM OS MODELOS}

\section{XBEACH E LITPROF}

\section{Índice de figuras}

Figura 1- Definição da zona de estudo na interface mar-terra: desde o limite da zona de rebentação das ondas até ao topo de praia ou duna que fica ao alcance da acção das ondas em condições extremas de agitação marítima e nível do mar. 3

Figura 2 - Evolução do perfil para o caso de verificação (envelope da observação experimental): a) perfil completo e b) pormenor

Figura 3 - Resultados numéricos do modelo XBeach com parâmetros por defeito à escala laboratorial (envelope da evolução): a) perfil completo e b) pormenor da zona activa.

Figura 4 - Resultados numéricos do modelo Litprof para as teorias de onda Stokes5 e D\&B com parâmetros por defeito à escala laboratorial (envelope da evolução): a) e c) perfil completo; b) e d) pormenor da zona activa......

Figura 5 - Resultados numéricos dos modelos XBeach e Litprof (para as teorias de onda Stokes5 e D\&B) com parâmetros por defeitos, à escala laboratorial, ao final de 0.1,0.3, 2.04 e 6 horas. A linha a azul representa a previsão XBeach, a linha amarelo representa a previsão Litprof-Stokes5, a linha verde representa a previsão Litprof-D\&B, a linha vermelha representa o perfil experimental e a linha preta representa o perfil inicial.

Figura 6 - Indicadores de impacto para os modelos XBeach e Litprof (para as teorias de onda Stokes5 e D\&B) com parâmetros por defeito: a) Volume de erosão, b) Recuo da duna e c) Recuo do topo da duna.

Figura 7 - Indicador de erro BSS para os modelos XBeach e Litprof (para as teorias de onda Stokes5 e D\&B) com parâmetros por defeito.

Figura 8 - Resultados numéricos do modelo XBeach, à escala laboratorial, ao final 6 horas. Teste aos parâmetros de calibração a) beta, b) break, c) facsl, d) facua, e) gammax, f) hmin, g) hswitch, h) Iws, i) turb, j) wets/p, k) dryslp e l) order.......................25

Figura 9 - Indicador de erro BSS para os testes de calibração do modelo XBeach. 25

Figura 10 - Resultados numéricos do modelo Litprof (para as teorias de onda Stokes5 e D\&B), à escala laboratorial, ao final 6 horas. Teste aos parâmetros de calibração a) $\gamma_{1}$, b) $\gamma_{2}$, c) $\alpha_{\text {scale }}$ e d) Maximum Angle of Bed Slope.

Figura 11 - Resultados numéricos do modelo Litprof (para as teorias de onda Stokes5 e D\&B), à escala laboratorial, ao final 6 horas. Teste aos parâmetros de calibração $\gamma_{2}$ e Maximum Angle of Bed Slope combinados.

Figura 12 - Indicador de erro BSS para os testes de calibração do modelo Litprof (para as teorias de onda Stokes5 e D\&B). Parâmetros de calibração: a) $\gamma_{1}$, b) $\gamma_{2}$, c) $\alpha_{\text {scale }}$ e d) Maximum Angle of Bed Slope. 29

Figura 13 - Indicador de erro BSS para os testes de calibração do modelo Litprof (Stokes5) para o teste de combinação dos parâmetros de calibração $\gamma_{2}$ e Maximum Angle of Bed Slope. 
Figura 14 - Resultados numéricos dos modelos XBeach e Litprof (para a teoria de onda Stokes5) com parâmetros por defeitos e após calibração, à escala laboratorial. As linhas turquesa e amarela representam as previsões do XBeach com parâmetros por defeito e calibrado, respectivamente; as linhas azul e verde representam as previsões do Litprof (Stokes5) com parâmetros por defeito e calibrado, respectivamente; a linha vermelha representa o perfil experimental; e a linha preta representa o perfil inicial.

Figura 15 - Indicadores de impacto para os modelos XBeach e Litprof (para a teoria de onda Stokes5) com parâmetros por defeito e após calibração: a) Volume de erosão, b) Recuo da duna e c) Recuo do topo da duna. 32

Figura 16 - Indicador de erro BSS para os modelos XBeach e Litprof (para a teoria de onda Stokes5) com parâmetros por defeito e após calibração. 


\section{EROSÃO DE DUNAS COM OS MODELOS}

\section{XBEACH E LITPROF}

Índice de tabelas

Tabela 1- Classificação proposta por van Rijn et al. (2003) e Sutherland et al. (2004).........................................................5

Tabela 2 - Parâmetros por defeito no modelo XBeach. …........................................................................................

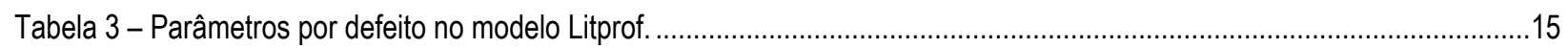




\title{
EROSÃO DE DUNAS COM OS MODELOS
}

\author{
XBEACH E LITPROF
}

\section{Introdução}

\subsection{Enquadramento, motivação e objectivos}

O estudo que aqui se descreve enquadra-se no âmbito do projecto "Dinâmica hidro-sedimentar do litoral a curto e médio prazo" do Plano de Investigação Programada (PIP) do LNEC para 2009-2012. Trata-se de um estudo na área da dinâmica costeira que visa melhorar a avaliação e previsão da vulnerabilidade/resiliência de sistemas dunares à acção das ondas em condições de tempestade marítima caracterizadas por fortes ventos, baixas pressões atmosféricas e curta duração (horas a dias). A motivação do estudo é o facto destes sistemas constituírem a mais importante defesa natural costeira na interface terra-mar e a sua erosão, galgamento, rotura e inundação durante estes eventos extremos constituir um elevado risco no que respeita a perda de território, degradação ambiental, destruição de património e até perda de vidas humanas.

Dada a complexidade dos processos costeiros que governam a dinâmica sedimentar na interface mar-terra, desde o limite da zona de rebentação das ondas até ao topo de praia ou duna que fica ao alcance da acção das ondas em condições extremas de agitação marítima e nível do mar, a simulação com modelos matemáticos, precisos e robustos para problemas de engenharia, da morfodinâmica de todas as subzonas (zona de rebentação, zona de espraiamento, topo de praia e sistema dunar) deste domínio espacial de forma contínua é bastante exigente, quer em termos de conhecimento dos processos físicos envolvidos quer em termos de recursos computacionais. 0 modelo XBeach (eXtreme Beach behaviour) (Roelvink et al., 2009), actualmente em fase de desenvolvimento e disponível à comunidade científica (em https://publicwiki.deltares.nl/display/XBEACH/Home), é um dos modelos mais promissores, dado que se trata de um modelo determinístico e está aberto a futuro desenvolvimento. 0 modelo Litprof (DHI, 2008) do sistema de modelação Litpack é um dos modelos mais eficazes nesta área, vastamente aplicado a nível mundial em projectos de investigação e consultoria, que, tendo a vantagem de ser um modelo determinístico, tal como o modelo XBeach, tem o inconveniente de não estar aberto a desenvolvimentos por parte da comunidade científica. $O$ objectivo deste estudo foi avaliar o desempenho de cada um dos modelos, XBeach e Litprof, na simulação numérica da erosão de dunas, e compará-los entre si.

Este estudo realizou-se na sequência de outro em que se avaliou o desempenho do modelo XBeach exclusivamente na simulação do desenvolvimento da barra submersa do perfil de erosão da praia (na ausência de recuo do topo de praia) e se comparou este desempenho com o do modelo Litprof (Oliveira, 2011).

Os modelos numéricos de erosão de dunas são geralmente verificados numa primeira fase com experiencias laboratoriais, em canais de grande escala, uma vez que estas permitem um maior controlo dos processos envolvidos, quer nas condições iniciais e de forçamento quer na monitorização da evolução, e consequentemente garantem maior confiança nos resultados. As condições em canal equivalem a uma praia uniforme ao longo da componente longitudinal. Só posteriormente, após uma satisfatória simulação numérica da componente transversal, faz sentido desenvolver estes modelos na 
dimensão longitudinal e nesta fase aplicá-los em casos de campo. 0 modelo XBeach já se encontra desenvolvido na componente longitudinal, no entanto, a complexidade dos processos na faixa costeira onde se aplica é particularmente tão elevada, que continua a ser necessário melhorar a sua abordagem transversal. Salienta-se que a importância do investimento científico no desenvolvimento da componente transversal deste tipo de modelos é tão grande que, na Holanda, onde os modelos de verificação da segurança dos sistemas dunares são de extrema importância para a gestão costeira, aplica-se o modelo empírico DUROS (Brandenburg, 2010), um modelo transversal desenvolvido para zonas costeiras uniformes com base em resultados de testes laboratoriais (Vellinga, 1986). 0 estudo aqui apresentado enquadra-se na primeira fase, em que o modelo é testado com experiencias laboratoriais, em canais de grande escala. Pretendeu-se simular um caso de erosão de uma duna experimental (escala 1:6) previamente realizado em laboratório no âmbito de um projecto de investigação.

A aplicação de ambos os modelos, mas principalmente do modelo XBeach, requer a introdução de um elevado número de parâmetros relativos aos processos físicos costeiros. Em projectos de engenharia, onde é de grande utilidade a aplicação deste tipo de modelos, acontece muitas vezes ser inviável a medição de alguns destes parâmetros. Para ultrapassar esta dificuldade, os autores de ambos os modelos recomendam a utilização de alguns valores por defeito (standard set of parameter settings). Neste artigo, apresentam-se os resultados dos modelos para o conjunto dos parâmetros por defeito recomendados e sugerem-se, no caso do modelo XBeach, e testam-se parâmetros de calibração. É com base na comparação dos dois conjuntos de resultados numéricos (que resultam da aplicação dos modelos com os parâmetros por defeito e dos modelos calibrados) com os resultados observados que se faz a avaliação do desempenho dos modelos XBeach e Litprof.

\subsection{Organização do relatório}

Para além da presente introdução onde se descreve o enquadramento, a motivação e os objectivos do estudo, este relatório divide-se em mais quatro capítulos e uma lista de referências. No capítulo seguinte, capítulo 2, descreve-se a abordagem metodológica utilizada. Esta descrição é realizada de forma mais pormenorizada para o modelo XBeach uma vez que a abordagem metodológica do modelo Litprof, mais conhecido e aplicado, já se encontra descrita pela autora em Oliveira (2001). No capítulo 3 descreve-se apenas a formulação do modelo XBeach, que se pretende vir a ser melhorada em futuros projectos de investigação coordenados ou participados pela autora, uma vez que a formulação do modelo Litprof já se encontra descrita pela autora em Oliveira (2001). No capítulo 4 apresentam-se e discutem-se os resultados de ambas as fases de teste dos modelos, ou seja, da fase de teste com os parâmetros por defeito e da fase de calibração. No capítulo 5 faz-se um sumário do estudo, retiram-se as principais conclusões e fazem-se recomendações de utilidade na aplicação dos dois modelos para casos de aplicação de erosão de dunas semelhantes. 


\section{Abordagem metodológica}

A erosão da zona costeira praia-duna resulta de uma acção de duas forças, a resistência da praia-duna decorrente das propriedades da mecânica de solos e a acção hidráulica decorrente da capacidade de transporte das ondas e correntes. A simulação matemática do fenómeno é bastante complexa pois exige a resolução precisa dos processos de hidrodinâmica, transporte sedimentar e morfodinâmica, em simultâneo ao longo das zonas de rebentação, espraiamento, topo de praia e duna (Figura 1).

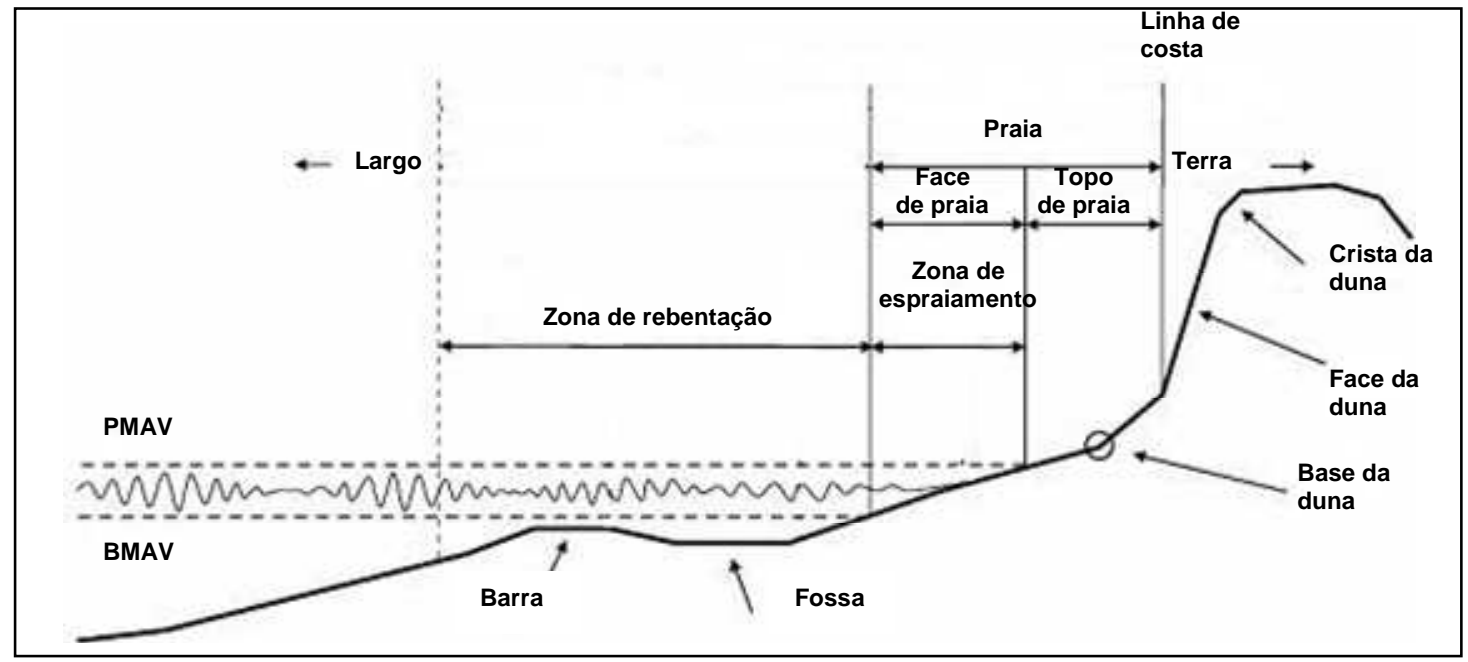

Figura 1- Definição da zona de estudo na interface mar-terra: desde o limite da zona de rebentação das ondas até ao topo de praia ou duna que fica ao alcance da acção das ondas em condições extremas de agitação marítima e nível do mar.

À semelhança do que acontece com outros processos físicos, a modelação numérica da erosão praia-duna pode caracterizar-se em três tipos de modelos conceptuais: empíricos, semi-empíricos e determinísticos ou baseados em processos. Do primeiro tipo, modelos empíricos, são os modelos onde existe uma relação explícita entre a erosão da praia-duna e importantes parâmetros físicos, que não são quantificados de forma individual mas sim através das consequências, ou seja, volume erodido e recuo da duna. O modelo DUROS (Brandenburg, 2010; Vellinga, 1986) aplicado na Holanda para verificação da segurança dos sistemas dunares é um exemplo deste tipo. Do segundo tipo, modelos semi-empíricos, são os modelos em que os principais processos físicos são individualmente descritos através de formulações matemáticas. O modelo SBeach (Larson e Kraus, 1989) é um exemplo deste tipo. Finalmente os modelos determinísticos, também vulgarmente designados por modelos baseados em processos, são os modelos em que os processos físicos são modelados individualmente. Os modelos numéricos aplicados neste estudo, o modelo XBeach e o modelo Litprof, são ambos deste tipo.

O modelo XBeach trata-se de um modelo bi-dimensional-horizontal constituído por vários sub-modelos dos processos costeiros propagação de ondas infragravíticas e grupos de ondas gravíticas, espraiamento, erosão e galgamento de dunas, avalanche, transporte sedimentar e evolução do fundo (Roelvink et al., 2010). O objectivo do XBeach é modelar estes processos nos quatro regimes de impacto de tempestade marítima definidos por Sallanger (2000): regime de espraiamento, regime de colisão, regime de galgamento e regime de inundação. Neste estudo em particular, apenas ocorrem os regimes de espraiamento e colisão, cuja abordagem metodológica se descreve abaixo.

Para além da contribuição das ondas curtas ou gravíticas, o escoamento da zona de espraiamento é em grande parte devido a ondas infragravíticas (que resultam de interacções harmónicas não lineares de grupos de ondas curtas) (Tucker, 1954). Guza e Thornton (1982) mostraram que a altura de onda da 
banda espectral correspondente às ondas infragravíticas aumenta linearmente com a altura significativa de onda ao largo, enquanto a energia correspondente às ondas curtas da banda espectral atinge um limite devido à dissipação ao longo da zona de rebentação. Com base nesta constatação, Raubenheimer e Guza (1996) mostraram que em condições de tempestade a componente devida às ondas infragravíticas é dominante no espraiamento. No modelo XBeach a dinâmica da zona de espraiamento é resolvida com base na acção bi-dimensional-horizontal de ondas de grupo e resultantes ondas infragravíticas sobre a batimetria. $O$ forçamento das ondas de grupo resulta da variação no tempo da acção da onda (Phillips, 1977) combinada com um modelo de dissipação para grupos de onda (Roelvink, 1993). É usado um modelo de turbulência (Svendsen, 1984; Nairn et al., 1990; Stive e Vriend, 1994) para representar o momento associado à turbulência superficial gerada pela rebentação que se desloca em direcção à costa.

As interacções harmónicas não lineares de grupos de ondas gravíticas geram ondas infragravíticas e correntes longitudinais e transversais à costa. A interacção onda-corrente na camada limite gera um aumento das tensões de atrito que afectam as ondas infragravíticas e correntes (Soulsby et al., 1993). A aleatoriedade das ondas incidentes é considerada com base na descrição de Feddersen et al. (2000), cuja aplicação (Ruessink et al., 2001) evidenciou uma boa estimativa das correntes longitudinais para um coeficiente de inércia constante.

Durante o regime de espraiamento e colisão o fluxo de massa transportado pelas ondas e pela turbulência superficial gerada pela rebentação retorna em direcção ao mar como escoamento de retorno. Este escoamento é responsável pelo processo de erosão, uma vez que é sob a sua acção que a areia é removida da face da duna em desmoronamento. Apesar de existirem várias propostas para o perfil vertical da corrente neste escoamento (Reniers et al., 2004b) a variação vertical da corrente em condições de tempestade não é muito grande, e por esse motivo ainda não foi introduzida no modelo XBeach.

Os processos de transporte de areia nas zonas de rebentação e espraiamento são bastante complexos pois resultam da combinação do movimento orbital de ondas curtas e longas, de correntes e da turbulência superficial gerada pela rebentação. $O$ transporte sedimentar induzido pela assimetria vertical e horizontal das ondas, que se estima inferior à contribuição dada pelas ondas longas e corrente média (van Thiel de Vries et al., 2008), é considerado através da formulação proposta por Soulsby (1997) num modelo que resolve os processos na zona de rebentação para ondas curtas propagadas em grupo. Esta formulação foi aplicada com sucesso na geração de correntes de retorno (Damgard et al., 2002; Reniers et al., 2004a) e rotura de ilhas barreira (Roelvink et al., 2003).

O modelo Litprof trata-se de um modelo bi-dimensional-vertical constituído por vários sub-modelos dos processos costeiros: um modelo de hidrodinâmica, um modelo quasi-tri-dimensional de transporte de sedimentos e um modelo morfológico (de evolução do fundo). A abordagem metodológica utilizada é descrita em Oliveira (2001) e DHI (2008). Este modelo não inclui os processos costeiros da zona de espraiamento. Neste estudo o modelo foi testado considerando duas teorias de onda, uma clássica e outra semi-empírica. A teoria de onda clássica considerada foi a teoria de $5^{\mathrm{a}}$ ordem de Stokes (Fenton, 1985) e a teoria semi-empírica considerada foi a teoria de Doering and Bowen (1995), na qual são consideradas parametrizações da onda para incluir as assimetrias horizontal e vertical.

Neste estudo utilizaram-se dois tipos de indicadores para avaliar o desempenho dos modelos: indicadores de impacto e de erro. Os indicadores de impacto foram o volume de erosão (por metro de comprimento longitudinal de praia) e o recuo da duna, definidos por

Volume de erosão $=\int_{z_{1}}^{z_{2}}($ perfil inicial - perfil pós - tempestade $) d z$ 
Recuo $=\left|x_{0}-x_{t}\right|$

sendo $z_{1}$ e $z_{2}$ a profundidade do ponto inicial do perfil e a cota do topo da duna, respectivamente; e $x_{0}$ e $x_{t}$ as coordenadas horizontais, a um determinado nível de referência (nível da água ou topo da duna) da duna frontal, no perfil inicial e no perfil pós-tempestade, respectivamente.

Sutherland et al. (2004) analisou diferentes métodos de medição de erro para avaliar o desempenho de modelos morfodinâmicos. Neste estudo a avaliação do desempenho dos modelos foi feita com base em três critérios, o erro sistemático ou tendenciosidade (bias), a precisão e a capacidade (skill) do modelo. 0 método aplicado foi o Brier Skill Score (BSS) de van Rijn et al. (2003), que compara previsões $\left(z_{b, c}\right)$ e medições de perfil $\left(z_{b, m}\right)$ com o perfil inicial $\left(z_{b, 0}\right)$ e tem em conta 0 erro de medição $\partial$ (que aqui se assumiu nulo). Define-se por

$$
B S S=1-\frac{\left\langle\left(\left|z_{b, c}-z_{b, m}\right|-\partial\right)^{2}\right\rangle}{\left\langle\left(z_{b, 0}-z_{b, m}\right)^{2}\right\rangle}
$$

onde os parêntesis angulares denotam a média.

Apresenta-se na Tabela 1 a classificação do desempenho de modelos morfodinâmicos proposta por van Rijn et al. (2003) e Sutherland et al. (2004).

Tabela 1- Classificação proposta por van Rijn et al. (2003) e Sutherland et al. (2004).

\begin{tabular}{l|c|c}
\hline & BSS (van Rijn et al., 2003) & BSS (Sutherland et al., 2004) \\
\hline Excelente & $1.0-0.8$ & $1.0-0.5$ \\
Bom & $0.8-0.6$ & $0.5-0.2$ \\
Razoável & $0.6-0.3$ & $0.2-0.1$ \\
Fraco & $0.3-0.0$ & $0.1-0.0$ \\
Mau & $<0.0$ & $<0.0$ \\
\hline
\end{tabular}




\section{Formulação do modelo XBeach}

O modelo resolve de forma acoplada as equações bi-dimensionais-horizontais de propagação de ondas, de escoamento, de transporte de sedimentos e de actualização do fundo (da continuidade), para condições de fronteira de espectro de ondas e escoamento não estacionárias. É utilizada uma malha estruturada alternada (staggered grid), rectilínea e não equidistante, implementada num sistema de coordenadas no qual o eixo-x está orientado em direcção à costa, i.e., perpendicular à linha de costa, e 0 eixo-y está orientado ao longo da costa.

Uma vez que as escalas de comprimento são pequenas, frequentemente ocorre escoamento supercrítico ( $\mathrm{Fr}>1$, sendo $\mathrm{Fr}$ o número de Froude) e se dá prioridade à estabilidade numérica, os esquemas de discretização numérica predominantes são de primeira ordem a montante (first order upwind), por forma a resolver os elevados gradientes da hidrodinâmica e morfodinâmica na zona de rebentação e espraiamento minimizando oscilações numéricas. São utilizados esquemas explícitos com passo de cálculo automático baseado no critério de Courant. Estes esquemas implementados numa malha estruturada alternada (staggered grid) garantem a robustez do modelo. Seguidamente descrevem-se de as principais equações governantes do modelo XBeach.

A equação da acção da onda é dada por

$$
\frac{\partial A}{\partial t}+\frac{\partial c_{x} A}{\partial x}+\frac{\partial c_{y} A}{\partial y}+\frac{\partial c_{\theta} A}{\partial \theta}=-\frac{D_{w}}{\sigma}
$$

onde

$$
\begin{aligned}
A(x, y, t, \theta)= & \frac{S_{w}(x, y, t, \theta)}{\sigma(x, y, t)} \\
c_{x}(x, y, t, \theta)= & c_{g} \cos (\theta)+u^{L} \\
c_{y}(x, y, t, \theta)= & c_{g} \operatorname{sen}(\theta)+v^{L} \\
c_{\theta}(x, y, t, \theta)= & \frac{\sigma}{\operatorname{senh} 2 k h}\left(\frac{\partial h}{\partial x} \operatorname{sen} \theta-\frac{\partial h}{\partial y} \cos \theta\right)+\cos \theta\left(\operatorname{sen} \theta \frac{\partial u}{\partial x}-\cos \theta \frac{\partial u}{\partial y}\right) \\
& +\operatorname{sen} \theta\left(\operatorname{sen} \theta \frac{\partial u}{\partial x}-\cos \theta \frac{\partial u}{\partial y}\right)
\end{aligned}
$$

sendo $\theta$ o ângulo de incidência relativamente ao eixo-x, $A(x, y, t, \theta)$ a acção da onda, $S_{w}$ a densidade de energia da onda em cada componente direccional, $\sigma$ a frequência intrínseca da onda obtida pela relação de dispersão linear, $c_{x}(x, y, t, \theta)$ e $c_{y}(x, y, t, \theta)$ as velocidades de propagação da acção da onda nas direcções x e y, respectivamente, $c_{g}$ a velocidade de grupo obtida pela teoria linear da onda, $u^{L} \mathrm{e} v^{L}$ as velocidades Lagrangianas médias em profundidade nas direcções transversal e longitudinal, respectivamente, $c_{\theta}(x, y, t, \theta)$ a velocidade de propagação no espaço- $\theta, \quad k$ o número de onda obtido pelas equações eikonel, $\omega$ a frequência obsoluta da onda, e $D_{w}$ a energia dissipada devido à rebentação, que se descreve abaixo.

A equação de dissipação da energia total, integrada no espectro direccional, devida à rebentação, é dada por 
$\bar{D}_{w}=\frac{\alpha}{\pi} Q_{b} \sigma E_{w}$

onde

$Q_{b}=1-\exp \left(-\left(\frac{H_{r m s}}{H_{\max }}\right)^{n}\right)$

$E_{w}(x, y, t)=\int_{0}^{2 \pi} S_{w}(x, y, t, \theta) d \theta$

sendo $\alpha=O(1), H=\sqrt{\frac{8 E_{w}}{\rho g}}, H_{r m s}$ a energia quadrática média, $H_{\max }=\frac{\gamma \tanh k h}{k}, \rho$ a densidade da água, $\gamma$ o índice de rebentação (parâmetro empírico) e $E_{w}(x, y, t)$ a energia total. No modelo assume-se que a energia total dissipada, $\bar{D}_{w}$, é distribuída proporcionalmente pelas componentes direccionais, sendo por isso

$D_{w}(x, y, t, \theta)=\frac{S_{w}(x, y, t, \theta)}{E_{w}(x, y, t)} \bar{D}_{w}(x, y, t)$.

Estimada a distribuição espacial da acção da onda e energia da onda, são calculadas as tensões de radiação, com base na teoria linear, da seguinte forma:

$$
\begin{aligned}
& S_{x x, w}(x, y, t)=\int\left(\frac{c_{g}}{c}\left(1+\cos ^{2} \theta\right)-\frac{1}{2}\right) S_{w} d \theta \\
& S_{x y, w}(x, y, t)=S_{y x, w}(x, y, t)=\int \operatorname{sen} \theta \cos \theta\left(\frac{c_{g}}{c} S_{w}\right) d \theta \\
& S_{y y, w}(x, y, t)=\int\left(\frac{c_{g}}{c}\left(1+\sin ^{2} \theta\right)-\frac{1}{2}\right) S_{w} d \theta
\end{aligned}
$$

onde $c=\frac{\sigma}{k}$.

A equação da energia de turbulência superficial gerada pela rebentação é acoplada à equação da acção/energia da onda na qual o termo de dissipação de energia da onda na rebentação é usado como fonte para turbulência superficial. Tal como para a acção da onda, é considerada a distribuição direccional da turbulência superficial mas o espectro de frequência é representado por uma única frequência média. A equação da turbulência superficial é dada por

$$
\frac{\partial S_{r}}{\partial t}+\frac{\partial c_{x} S_{r}}{\partial x}+\frac{\partial c_{y} S_{r}}{\partial y}+\frac{\partial c_{\theta} S_{r}}{\partial \theta}=-D_{r}+D_{w}
$$

onde

$$
\begin{aligned}
& c_{x}(x, y, t, \theta)=c \cos (\theta)+u^{L} \\
& c_{y}(x, y, t, \theta)=c \operatorname{sen}(\theta)+v^{L}
\end{aligned}
$$

sendo $S_{r}(x, y, t, \theta)$ a componente direccional da energia de turbulência superficial, $c_{x}(x, y, t, \theta) \mathrm{e}$ $c_{y}(x, y, t, \theta)$ as velocidades de propagação da energia de turbulência superficial nas direcções $\mathrm{x}$ e $\mathrm{y}$, 
respectivamente, e a velocidade de propagação no espaço- $\theta, c_{\theta}(x, y, t, \theta)$, semelhante à expressão (8), assumindo assim que as ondas e a turbulência superficial se propagam na mesma direcção. $A$ velocidade de fase, $c=\sigma / k$, é obtida através da teoria linear da onda. A dissipação da turbulência superficial por componente direccional da onda, $D_{r}(x, y, t, \theta)$, resulta da distribuição da dissipação total da turbulência superficial proporcionalmente pelas componentes direccionais da onda, sendo por isso

$$
D_{r}(x, y, t, \theta)=\frac{S_{r}(x, y, t, \theta)}{E_{r}(x, y, t)} \bar{D}_{r}(x, y, t)
$$

onde

$\bar{D}_{r}=\frac{2 g \beta_{r} E_{r}}{c}$.

A contribuição da turbulência superficial para as tensões de radiação é dada por

$$
\begin{aligned}
& S_{x x, r}(x, y, t)=\int \cos ^{2} \theta S_{r} d \theta \\
& S_{x y, r}(x, y, t)=S_{y x, r}(x, y, t)=\int \operatorname{sen} \theta \cos \theta S_{r} d \theta \\
& S_{y y, r}(x, y, t)=\int \operatorname{sen}^{2} \theta S_{r} d \theta .
\end{aligned}
$$

Esta contribuição é adicionada às tensões calculadas em (12), (13) e (14). O resultante tensor das tensões de radiação é

$$
\begin{aligned}
& F_{x}(x, y, t)=-\left(\frac{\partial S_{x x, w}+\partial S_{x x, r}}{\partial x}+\frac{\partial S_{x y, w}+\partial S_{x y, r}}{\partial y}\right) \\
& F_{y}(x, y, t)=-\left(\frac{\partial S_{x y, w}+\partial S_{x y, r}}{\partial x}+\frac{\partial S_{y y, w}+\partial S_{y y, r}}{\partial y}\right) .
\end{aligned}
$$

O sistema de equações para o escoamento para águas pouco profundas é dado por

$$
\begin{aligned}
& \frac{\partial u^{L}}{\partial t}+u^{L} \frac{\partial u^{L}}{\partial x}+v^{L} \frac{\partial u^{L}}{\partial y}-f v^{L}-v_{h}\left(\frac{\partial^{2} u^{L}}{\partial x^{2}}+\frac{\partial^{2} u^{L}}{\partial y^{2}}\right)=\frac{\tau_{s x}}{\rho h}-\frac{\tau_{b x}^{E}}{\rho h}-g \frac{\partial \eta}{\partial x}+\frac{F_{x}}{\rho h} \\
& \frac{\partial v^{L}}{\partial t}+u^{L} \frac{\partial v^{L}}{\partial x}+v^{L} \frac{\partial v^{L}}{\partial y}+f u^{L}-v_{h}\left(\frac{\partial^{2} v^{L}}{\partial x^{2}}+\frac{\partial^{2} v^{L}}{\partial y^{2}}\right)=\frac{\tau_{s y}}{\rho h}-\frac{\tau_{b y}^{E}}{\rho h}-g \frac{\partial \eta}{\partial y}+\frac{F_{y}}{\rho h} \\
& \frac{\partial \eta}{\partial t}+\frac{\partial h u^{L}}{\partial x}+\frac{\partial h v^{L}}{\partial y}=0
\end{aligned}
$$

onde as equações do momento e continuidade são formuladas em termos de velocidade Lagrangiana (definida como a distância a que uma partícula de água se desloca num período de onda, dividida por esse período). Esta velocidade relaciona-se com a velocidade Euleriana (a velocidade média da onda curta num ponto fixo) da seguinte forma

$u^{L}=u^{E}+u^{S}$ e $v^{L}=v^{E}+v^{S}$

sendo $u^{S}$ e $v^{S}$ as velocidades de Stokes nas direcções $\mathrm{x}$ e y, respectivamente, dadas por 
$u^{S}=\frac{E_{w} \cos \theta}{\rho h c} \mathrm{e} v^{S}=\frac{E_{w} \operatorname{sen} \theta}{\rho h c}$.

Os parâmetros $\tau_{s x}$ e $\tau_{s y}$ são as tensões devidas ao vento, $\tau_{b x}^{E}$ e $\tau_{b y}^{E}$ são as tensões de atrito no fundo (calculadas com velocidades Eulerianas), $\eta$ é o nível da água, $h$ é a profundidade, $v_{h}$ é a viscosidade horizontal, $f$ é o coeficiente de Coriolis e $F_{x}$ e $F_{y}$ são as tensões induzidas pelas ondas.

A equação de advecção difusão para transporte de sedimentos é dada por

$$
\frac{\partial h C}{\partial t}+\frac{\partial h C u^{E}}{\partial x}+\frac{\partial h C v^{E}}{\partial y}+\frac{\partial}{\partial x}\left(D_{h} h \frac{\partial C}{\partial x}\right)+\frac{\partial}{\partial y}\left(D_{h} h \frac{\partial C}{\partial y}\right)=\frac{h C_{e q}-h C}{T_{s}}
$$

onde

$$
C_{e q}=\frac{A_{s b}+A_{s s}}{h}\left(\left(\left|u^{E}\right|^{2}+0.018 \frac{u_{r m s}^{2}}{C_{d}}\right)^{0.5}-u_{c r}\right)^{2.4}\left(1-\alpha_{b} m\right)
$$

sendo $C$ a concentração de sedimentos média em profundidade, que varia na escala temporal do grupo de onda, $D_{h}$ o coeficiente de difusão de sedimentos, $T_{s}$ o tempo de mobilização dos sedimentos definido como $T_{s}=\max \left(0.05 \frac{h}{w_{s}}, 0.2\right) s, w_{s}$ a velocidade de queda, $C_{e q}$ a concentração de equilíbrio de sedimentos, $u_{c r}$ a velocidade crítica, $C_{d}$ o coeficiente de inércia apenas devido ao escoamento (sem considerar o efeito das ondas curtas), $\alpha_{b}$ o parâmetro de calibração e $A_{s b}$ e $A_{s s}$ os coeficientes de transporte de fundo e em suspensão, respectivamente, que são dependentes do tamanho e densidade do sedimento e da profundidade.

A equação de avalanche utilizada é dada pela expressão

$$
\left|\frac{\partial z_{b}}{\partial x}\right|>m_{c r}
$$

onde $m_{c r}$ é o declive crítico. O processo de avalanche é accionado quando o declive entre as duas últimas células molhadas por uma elevada altura de onda infragravítica é superior ao declive crítico. Nessa altura, dá-se a passagem de um volume de sedimentos de uma célula para a outra de forma a satisfazer a condição de declive crítico entre essas duas células.

A equação da actualização do fundo (da continuidade) é dada por

$$
\frac{\partial z_{b}}{\partial t}+\frac{f_{m o r}}{(1-p)}\left(\frac{\partial q_{x}}{\partial x}+\frac{\partial q_{y}}{\partial y}\right)=0
$$

onde

$$
\begin{aligned}
& q_{x}(x, y, t)=\left(\frac{\partial h C u^{E}}{\partial x}\right)+\left[\frac{\partial}{\partial x}\left(D_{h} h \frac{\partial C}{\partial x}\right)\right] \\
& q_{y}(x, y, t)=\left(\frac{\partial h C v^{E}}{\partial y}\right)+\left[\frac{\partial}{\partial y}\left(D_{h} h \frac{\partial C}{\partial y}\right)\right]
\end{aligned}
$$

Sendo $p$ a porosidade, $f_{\text {mor }}$ um factor de aceleração morfológica de $O(1-10)$, e $q_{x}$ e $q_{y}$ as taxas de transporte sedimentar nas direcções x e y, respectivamente. 


\section{Resultados}

\subsection{Caso de verificação}

Este caso de teste do modelo, descrito em WL | Delft Hydraulics (2006) como teste T01, diz respeito a um perfil de referência com uma duna bastante robusta. A escolha deste caso de verificação deve-se ao facto dele ser ideal para testar o desempenho dos modelos XBeach e Litprof na erosão de dunas, pois para além de incluir uma duna bastante robusta na sua configuração geométrica, conforme salientado, foi realizado em canal de grande escala (factor de escala profundidade $n_{d}$ igual a 6). Trata-se de um perfil com declive 1:20 desde o fundo, ao nível $-4.5 \mathrm{~m}$, até aproximadamente ao nível $-2.7 \mathrm{~m}$, seguido de um declive 1:70 até aproximadamente ao nível $-0.8 \mathrm{~m}$, seguido de um declive 1:20 até aproximadamente ao nível $-0.3 \mathrm{~m}$, e finalmente de um declive de 1:3 até ao topo da duna (Figura 2). 0 sedimento utilizado caracteriza-se por $\mathrm{D} 50=0.2 \mathrm{~mm}, \mathrm{D} 90=0.3 \mathrm{~mm}$ e densidade 2.65 . 0 teste foi realizado à temperatura aproximada de $9^{\circ} \mathrm{C}$ em modelo reduzido à escala 1:6. As condições de onda incidente foram um espectro de Pierson-Moskowitz com altura significativa $\mathrm{Hs}=1.5 \mathrm{~m}$, período de pico $\mathrm{Tp}=4.9 \mathrm{~s}$ e duração 6 horas. 0 teste foi temporariamente interrompido para realizar medições do fundo a 0.1, 0.3, 1, 2.04 e 6 horas a contar a partir do início da experiencia laboratorial. Os intervalos no início do teste foram mais curtos porque no início de um teste as taxas de erosão são mais elevadas. Da acção das ondas resultou um perfil de erosão caracterizado por um forte recuo da duna: aproximadamente $9 \mathrm{~m}^{3} \cdot \mathrm{m}^{-1}$ foram extraídos da duna frontal, correspondendo este volume a um recuo de aproximadamente $2 \mathrm{~m}$ ao nível da água e de aproximadamente $4.8 \mathrm{~m}$ ao nível do topo da duna (conforme eq. (2) de definição de recuo). A erosão da duna não se deu gradualmente mas sim por etapas, i.e., em determinados instantes ocorreu 0 deslizamento de blocos de duna com volume razoável. Este processo de avalanche ocorreu quando o declive da duna era quase vertical ou mesmo ligeiramente negativo (quando o topo de duna estava já pendurado). Observou-se ainda que o instante de avalanche (de deslizamento dos blocos de duna) nem sempre coincidiu com o instante de impacto da onda. Relativamente à morfologia do perfil de erosão, observou-se que nos primeiros instantes, em que a taxa de erosão é mais elevada, o volume de areia erodido da duna foi depositado na zona do perfil submerso imediatamente adjacente formando um declive de praia mais suave. Posteriormente, com o decorrer do processo erosivo, formou-se uma barra submersa não muito pronunciada na zona de deposição de areia mais afastada da face de praia e duna (Figura 2).

A avaliação do desempenho dos dois modelos, XBeach e Litprof, para este caso de verificação foi realizada em duas fases. Numa primeira fase testaram-se os modelos com os parâmetros por defeito. Numa segunda fase calibraram-se os modelos, ajustando os parâmetros de forma a melhorar o seu desempenho, i.e., a similaridade com os resultados observados. Em cada uma das fases compararam-se os resultados de ambos, sempre com base nos resultados observados durante a evolução do perfil experimental. 
a)

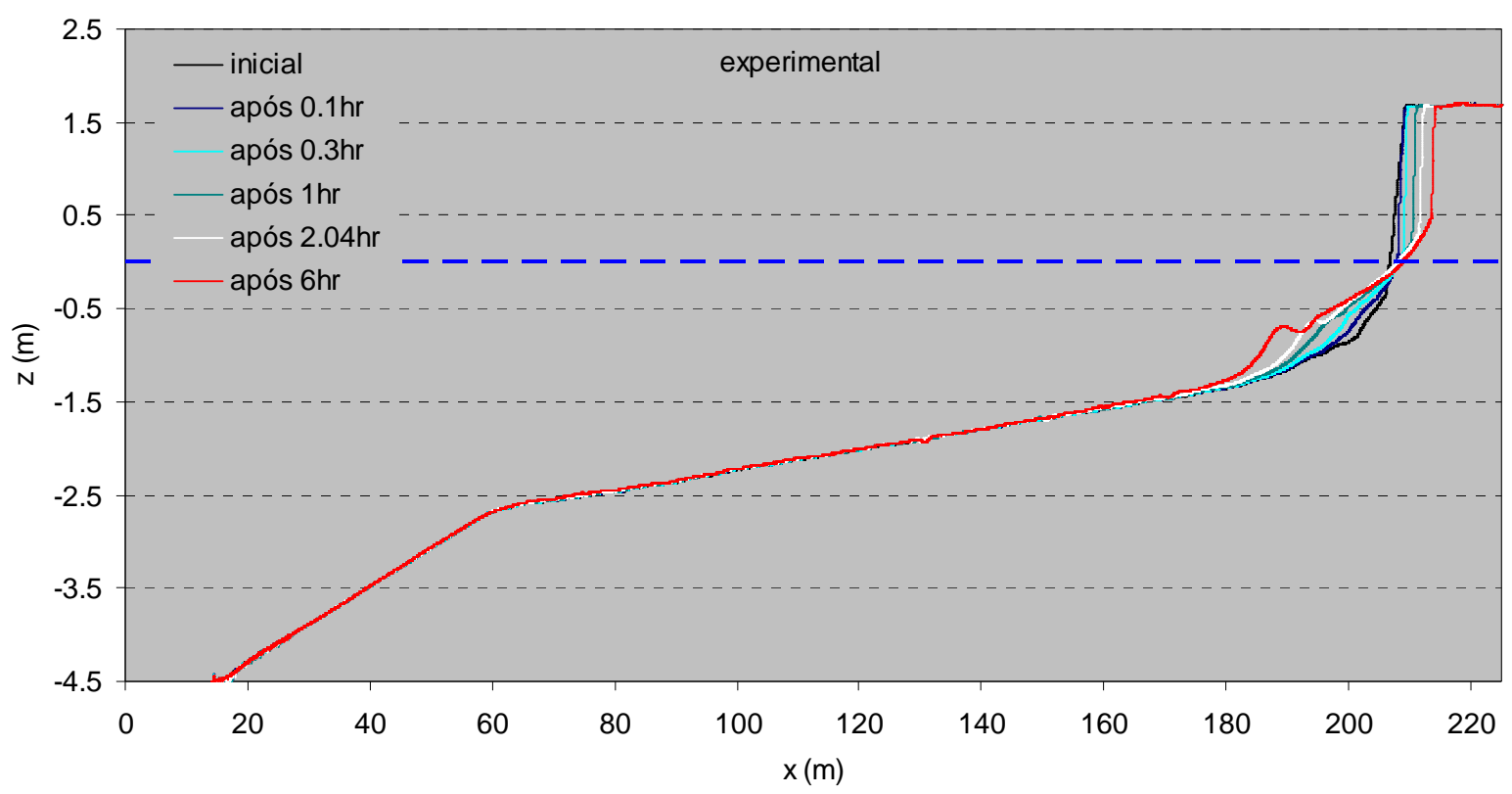

b)

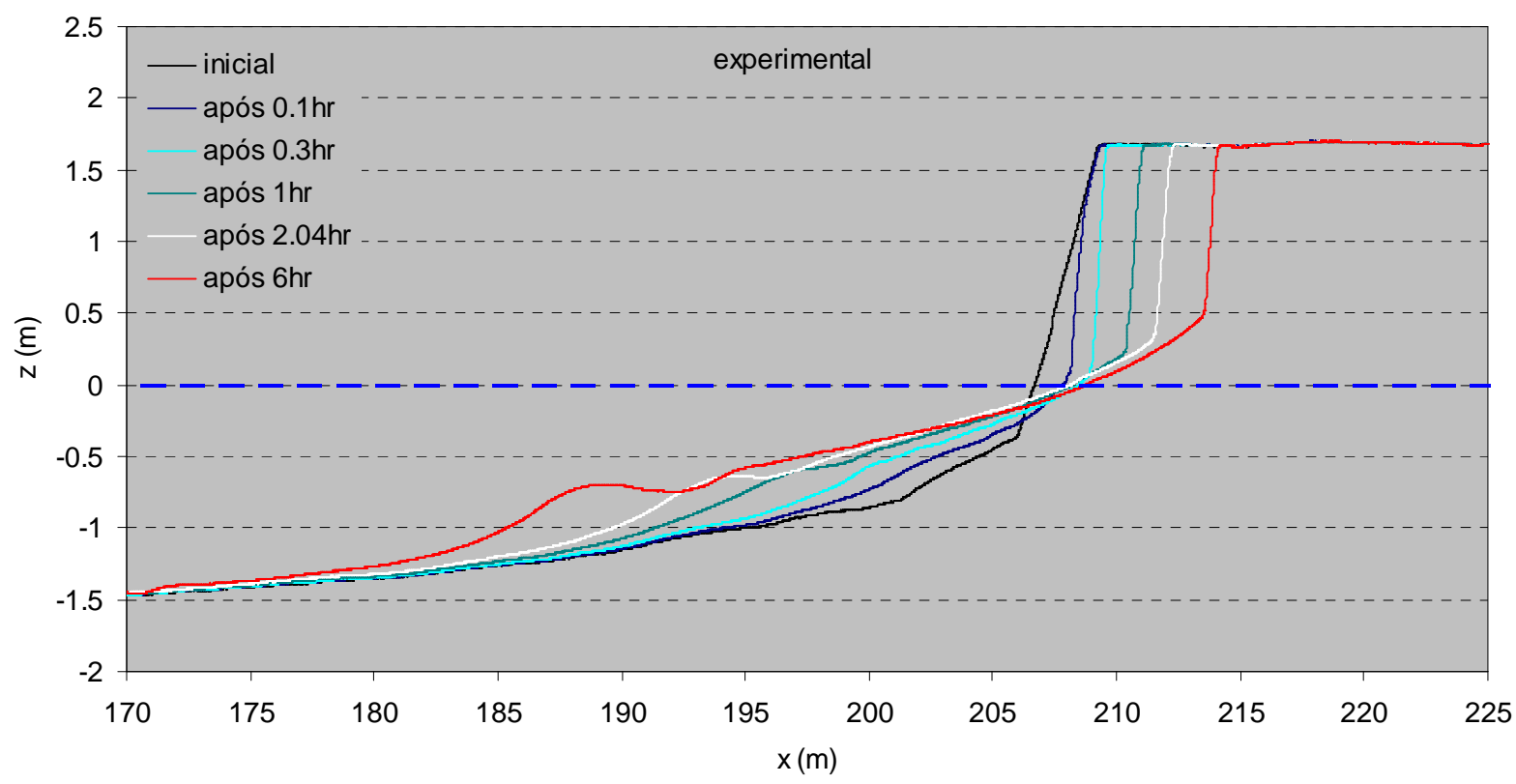

Figura 2 - Evolução do perfil para o caso de verificação (envelope da observação experimental): a) perfil completo e b) pormenor.

\subsection{Avaliação com parâmetros por defeito}

A aplicação de modelos de morfodinâmica requer a introdução de um elevado número de parâmetros relativos aos processos físicos costeiros. Em projectos de engenharia, onde é de grande utilidade a aplicação deste tipo de modelos, acontece muitas vezes ser inviável a medição de alguns destes parâmetros. Para ultrapassar esta dificuldade, os autores dos modelos recomendam a utilização de alguns valores por defeito, encontrados com base na execução de um elevado número de testes submetidos à mais vasta gama de condições possivel. Contudo, no modelo XBeach existe um elevado 
número de possíveis parâmetros de calibração, o que faz com que o modelo tenha um elevado potencial para reproduzir correctamente os processos envolvidos mas também seja bastante exaustivo 0 procedimento de teste que conduz à sua correcta aplicação. Seguidamente descrevem-se as aplicações dos modelos XBeach e Litprof com os parâmetros por defeito e faz-se a sua comparação.

\subsubsection{Modelo XBeach}

Após análise dos dois conjuntos de valores dos parâmetros por defeito sugeridos pelos autores em Roelvink et al. (2009) e Roelvink et al. (2010), optou-se para este caso de estudo por atribuir um novo conjunto de valores aos parâmetros por defeito, o mesmo conjunto utilizado pela autora para o teste do modelo XBeach no caso do desenvolvimento de uma barra submersa sem erosão do topo de praia (Oliveira, 2011). Fez-se constituir esse conjunto por: para os parâmetros com valor igual em ambos os conjuntos, por esse valor; e para os restantes parâmetros, pelo valor atribuído para os casos teste Lip11d-2E, Deltaflume_2005_T04, Zelt, Delilah e Zwin (Roelvink et al., 2009), sendo os dois primeiros testes laboratoriais e os restantes três testes de campo (Zelt e Delilah nos USA, Zwin na Europa). Apresentam-se na Tabela 2 os valores de alguns dos parâmetros por defeito atribuídos neste estudo onde se usou uma malha de espaçamento horizontal de $1 \mathrm{~m}$.

Tabela 2 - Parâmetros por defeito no modelo XBeach.

\begin{tabular}{|c|c|c|c|}
\hline & Parâmetro 1 & Descrição [unidades] & Valor por defeito \\
\hline \multirow{12}{*}{ 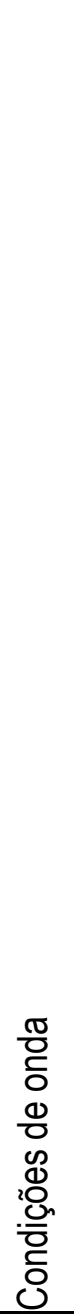 } & break & $\begin{array}{ll}\text { Opção formulação } & \text { rebentação } \\
\text { (3="Roelvink2") [-] } & \end{array}$ & 3 \\
\hline & wci & Opção interacção onda corrente [-] & 0 \\
\hline & roller & Opção modelo de turbulência superficial [-] & 1 \\
\hline & beta & $\begin{array}{l}\text { Coeficiente do declive do rolo no modelo de } \\
\text { turbulência superficial }(>0.05 \mathrm{e}<0.3)[-]\end{array}$ & 0.1 \\
\hline & gamma & $\begin{array}{l}\text { Parâmetro de rebentação na formulação de } \\
\text { Baldock ou Roelvink [-] }\end{array}$ & 0.55 \\
\hline & gammax & $\begin{array}{l}\text { Razão máxima altura onda/profundidade } \\
(\mathrm{Hrms} / \mathrm{hmax})[-]\end{array}$ & 2 \\
\hline & alpha & Coeficiente de dissipação da onda [-] & 1 \\
\hline & delta & $\begin{array}{l}\text { Fracção da altura de onda a adicionar à } \\
\text { profundidade [-] }\end{array}$ & 0 \\
\hline & $\mathrm{n}$ & $\begin{array}{l}\text { Potencia no modelo de dissipação de } \\
\text { Roelvink [-] }\end{array}$ & 10 \\
\hline & scheme & $\begin{array}{l}\text { Opção esquema numérico para equação } \\
\text { acção da onda (1=Upwind; } 2=\text { Lax Wendroff) } \\
{[-]}\end{array}$ & 2 \\
\hline & Iws & $\begin{array}{l}\text { Opção ondas infragravíticas }(0=\text { não; } 1=\operatorname{sim}) \\
{[-]}\end{array}$ & 0 \\
\hline & instat & $\begin{array}{l}\text { Grupos de onda gerados com parâmetros } \\
\text { espectrais [-] }\end{array}$ & 4 \\
\hline
\end{tabular}




\begin{tabular}{|c|c|c|c|}
\hline \multirow{5}{*}{ 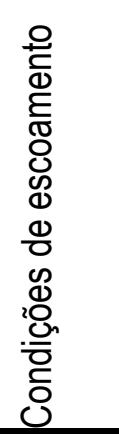 } & C & Coeficiente de Chezy $\left[\mathrm{m}^{1 / 2} / \mathrm{s}\right]$ & 65 \\
\hline & nuh & Viscosidade horizontal [m²/s] & 0.1 \\
\hline & nuhfac & $\begin{array}{l}\text { Coeficiente de calibração da viscosidade } \\
\text { horizontal do modelo de Battjes [-] }\end{array}$ & 1 \\
\hline & eps & Profundidade mínima para inundação [m] & 0.001 \\
\hline & hmin & $\begin{array}{l}\text { Profundidade mínima para cálculo da } \\
\text { velocidade da corrente de retorno }[\mathrm{m}]\end{array}$ & 0.05 \\
\hline \multirow{8}{*}{ 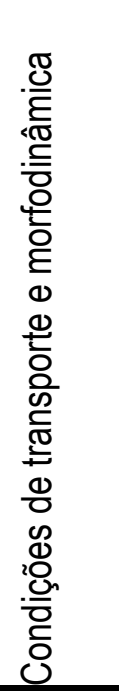 } & hswitch & $\begin{array}{l}\text { Profundidade mínima (na interface de } \\
\text { wetslp para drys } \mid \mathrm{p} \text { ) }[\mathrm{m}]\end{array}$ & 0.1 \\
\hline & wetslp & Declive crítico de avalanche submersa [-] & 0.3 \\
\hline & dryslp & Declive crítico de avalanche emersa [-] & 1 \\
\hline & morfac & Factor morfológico [-] & 1 \\
\hline & dico & Coeficiente de dispersão horizontal [m²/s] & 1 \\
\hline & facsl & $\begin{array}{l}\text { Factor declive na formulação do transporte } \\
\text { de sedimentos [-] }\end{array}$ & 1.6 \\
\hline & turb & $\begin{array}{l}\text { Opção cálculo concentração sedimentar de } \\
\text { equilíbrio [-] }\end{array}$ & 2 \\
\hline & facua & Opção de assimetria de ondas curtas [-] & 0 \\
\hline 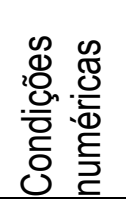 & CFL & $\begin{array}{l}\text { Máximo número de Courant para estimar o } \\
\text { passo de cálculo automaticamente }[-]\end{array}$ & 0.9 \\
\hline \multirow{5}{*}{ 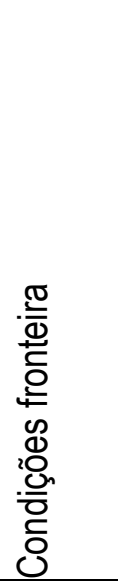 } & order & $\begin{array}{l}\text { Geração de ondas }\left(1=1^{a} \text { ordem; } 2=2^{a}\right. \\
\text { ordem })[-]\end{array}$ & 1 \\
\hline & front & $\begin{array}{l}\text { Condição fronteira lado mar }(0=\text { condição } \\
\text { geração-absorção, em 1D) [-] }\end{array}$ & 0 \\
\hline & back & $\begin{array}{l}\text { Condição fronteira lado terra (2=condição } \\
\text { geração-absorção, em 2D) [-] }\end{array}$ & 2 \\
\hline & left & $\begin{array}{l}\text { Condição fronteira lateral esquerda } \\
(0=\text { Newmann) }[-]\end{array}$ & 0 \\
\hline & right & $\begin{array}{l}\text { Condição fronteira lateral direita } \\
(0=\text { Newmann) }[-]\end{array}$ & 0 \\
\hline
\end{tabular}

1 designação de acordo com as variáveis introduzidas no modelo

Os resultados (Figura 3) mostram que o modelo XBeach com os parâmetros por defeito simula de forma razoável a acção erosiva das ondas na quase totalidade do perfil. As maiores diferenças relativamente aos resultados experimentais encontram-se no declive da duna, que se observou quase vertical durante a experiência laboratorial e o modelo reproduz mais suave, e na barra submersa formada na extremidade da zona activa do perfil (para valores de x entre 185 e 192 m), que o modelo não reproduz. 
a)

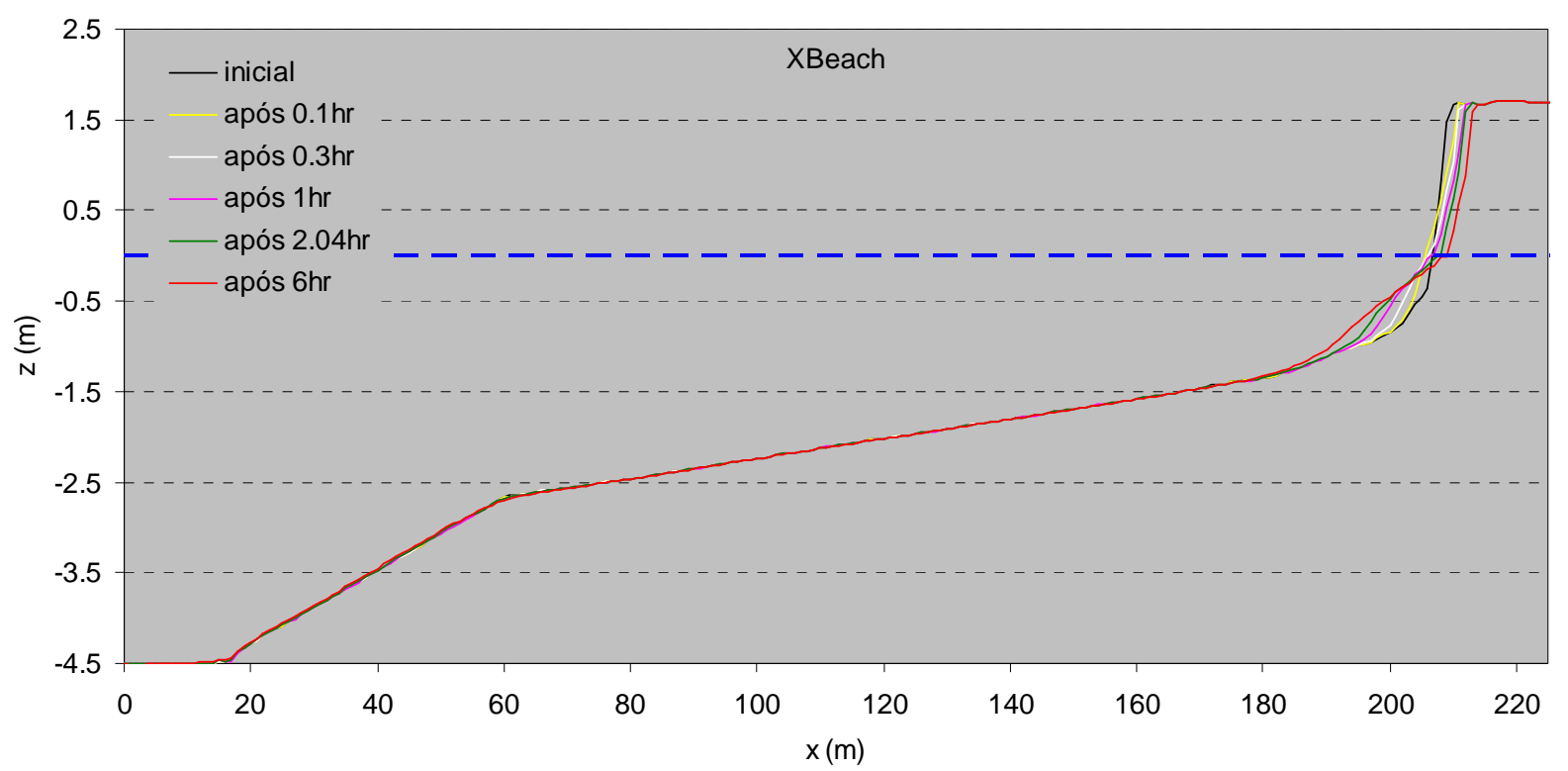

b)

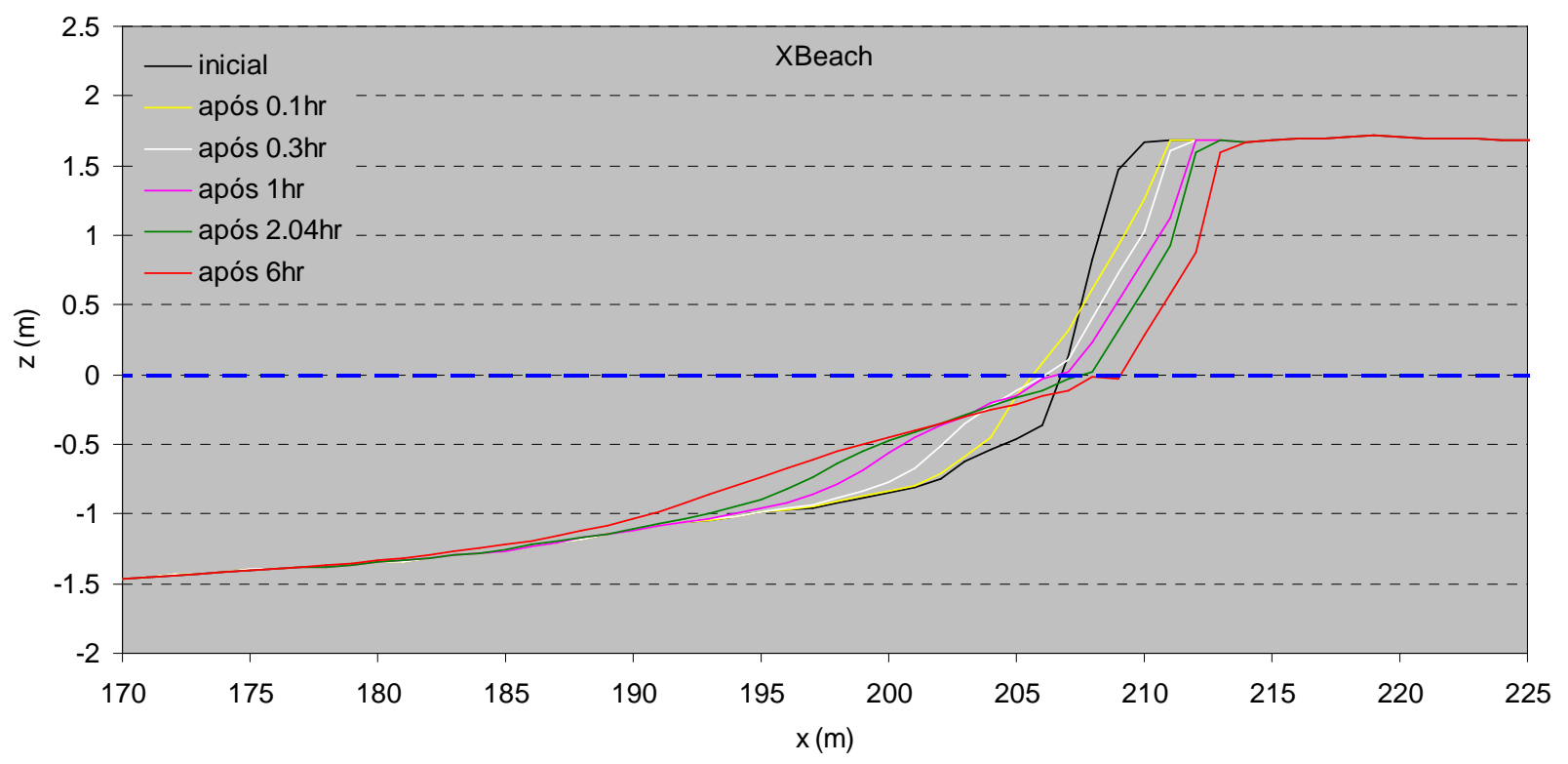

Figura 3 - Resultados numéricos do modelo XBeach com parâmetros por defeito à escala laboratorial (envelope da evolução): a) perfil completo e b) pormenor da zona activa.

\subsubsection{Modelo Litprof}

Aplicou-se o modelo Litprof com os parâmetros por defeito recomendados pelos autores. Descrevem-se na Tabela 3 os parâmetros de calibração atribuídos. Testaram-se duas teorias de onda, a teoria de Doering e Bowen (1995) (B\&D) e a teoria de $5^{\mathrm{a}}$ ordem de Stokes (Fenton, 1985) (Stokes5). 
Tabela 3 - Parâmetros por defeito no modelo Litprof.

\begin{tabular}{|c|c|c|c|}
\hline & Parâmetro ${ }^{1}$ & Descrição [unidades] & Valor por defeito \\
\hline \multirow{7}{*}{ 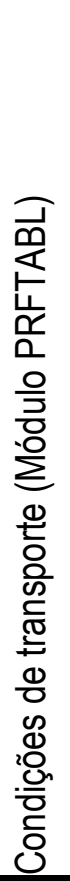 } & $\mathrm{C} 1$ & $\begin{array}{l}\text { Parâmetro de descrição das rugas de } \\
\text { fundo [-] }\end{array}$ & 0.1 \\
\hline & $\mathrm{C} 2$ & $\begin{array}{l}\text { Parâmetro de descrição das rugas de } \\
\text { fundo [-] }\end{array}$ & 2 \\
\hline & $\mathrm{C} 3$ & $\begin{array}{l}\text { Parâmetro de descrição das rugas de } \\
\text { fundo [-] }\end{array}$ & 16 \\
\hline & $\mathrm{C} 4$ & $\begin{array}{l}\text { Parâmetro de descrição das rugas de } \\
\text { fundo [-] }\end{array}$ & 3 \\
\hline & $\theta_{c}$ & Parâmetro crítico de Shields [-] & 0.045 \\
\hline & $\begin{array}{l}\text { Convective } \\
\text { terms }\end{array}$ & $\begin{array}{l}\text { Opção inclusão da corrente de fundo } \\
\text { (streaming) [-] }\end{array}$ & included \\
\hline & $C_{b}$ & $\begin{array}{l}\text { Opção de cálculo da concentração de } \\
\text { fundo (modelo determinístico de Engelund } \\
\text { and Fredsøe (1976) ou empírico de } \\
\text { Zyserman e Fredsoe (1994)) [-] }\end{array}$ & deterministic \\
\hline \multirow{3}{*}{ 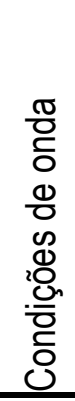 } & $\gamma_{1}$ & $\begin{array}{l}\text { Máxima razão entre a altura e o } \\
\text { comprimento de onda }(\mathrm{H} / \mathrm{L})[-]\end{array}$ & 0.88 \\
\hline & $\gamma_{2}$ & $\begin{array}{l}\text { Máxima razão entre a altura de onda e a } \\
\text { profundidade }(H / h)[-]\end{array}$ & 0.6 \\
\hline & $\beta$ & $\begin{array}{l}\text { Parâmetro empírico do modelo de } \\
\text { turbulência superficial de Dally e Brown } \\
(1995)(>0.1 \mathrm{e}<0.2)[-]\end{array}$ & 0.15 \\
\hline \multirow{5}{*}{ 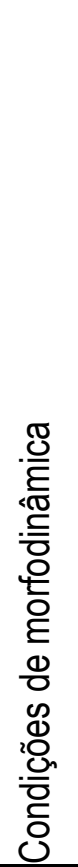 } & $\begin{array}{l}\text { Maximum } \\
\text { Morphological } \\
\text { Timestep }\end{array}$ & $\begin{array}{l}\text { Limite máximo do intervalo de tempo entre } \\
\text { actualizações da batimetria, sendo o } \\
\text { passo de cálculo do estimado } \\
\text { automaticamente [s] }\end{array}$ & 1800 \\
\hline & $\begin{array}{l}\text { Maximum } \\
\text { Angle of Bed } \\
\text { Slope }\end{array}$ & $\begin{array}{l}\text { Máximo declive de fundo antes de } \\
\text { avalanche submersa }\left[^{\circ}\right]\end{array}$ & 30 \\
\hline & $\begin{array}{l}\alpha_{\text {scale }} \text { or scale } \\
\text { parameter }\end{array}$ & $\begin{array}{l}\text { Factor de transferência de momento } \\
\text { transversal (afecta a forma da barra } \\
\text { submersa) [-] }\end{array}$ & 1 \\
\hline & Clay layer & $\begin{array}{l}\text { Opção de inclusão de um fundo rígido } \\
\text { abaixo de determinado nível (ao qual pode } \\
\text { ocorrer acumulação mas não erosão) [-] }\end{array}$ & exclude \\
\hline & $\begin{array}{l}\text { Energy loss } \\
\text { due to bed } \\
\text { friction }\end{array}$ & $\begin{array}{l}\text { Opção de inclusão de dissipação de } \\
\text { energia por atrito de fundo segundo o } \\
\text { modelo de Fredsøe e Deigaard (1992) [-] }\end{array}$ & include \\
\hline
\end{tabular}

1 designação de acordo com a nomenclatura das variáveis na interface do modelo 
Comparando os resultados do modelo Litprof com os parâmetros por defeito para ambas as teorias de onda consideradas com os resultados experimentais, constata-se que o modelo Litprof não simula o perfil de erosão caracterizado por um forte recuo da duna observado experimentalmente (Figura 4a-d).

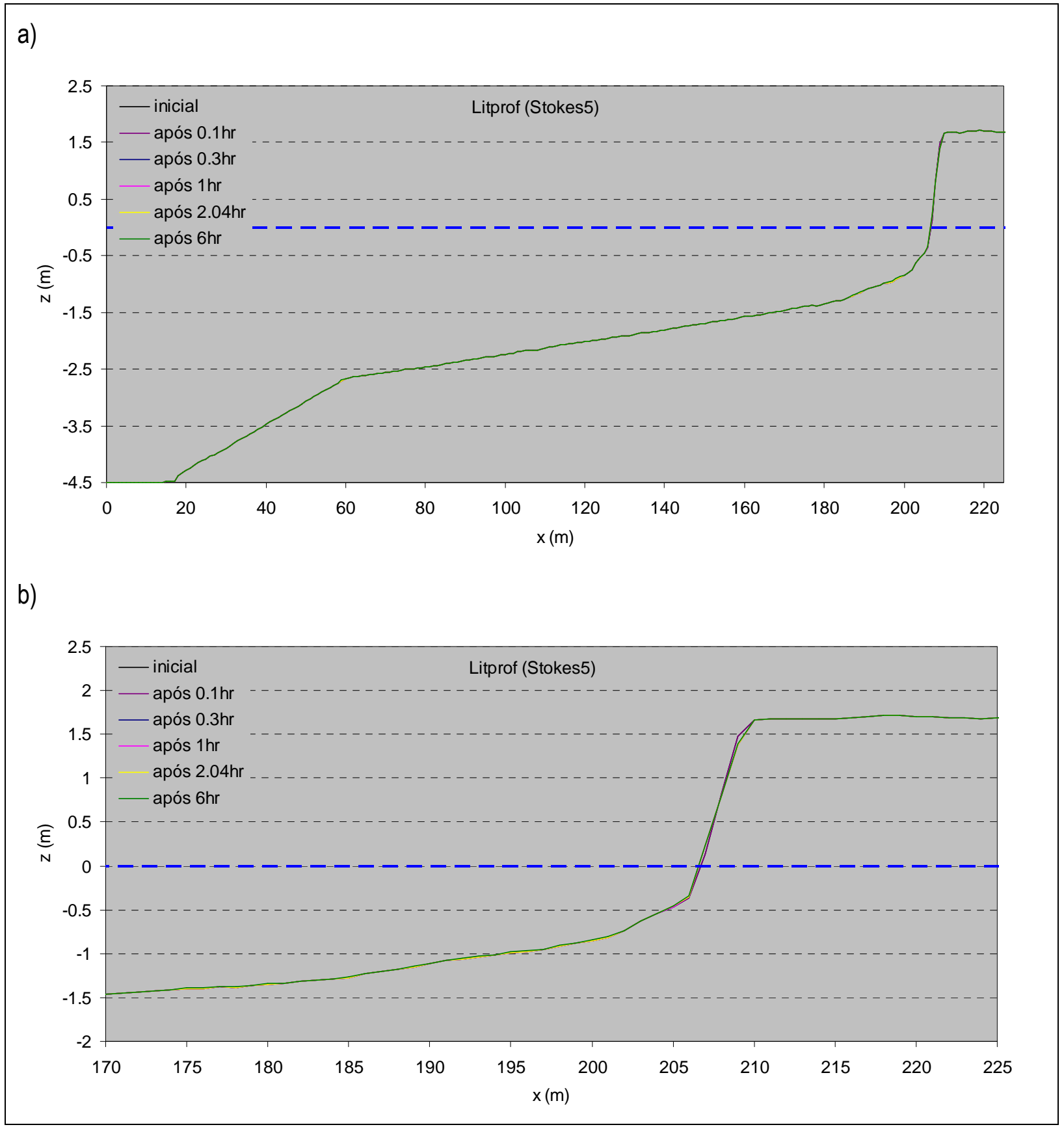


c)

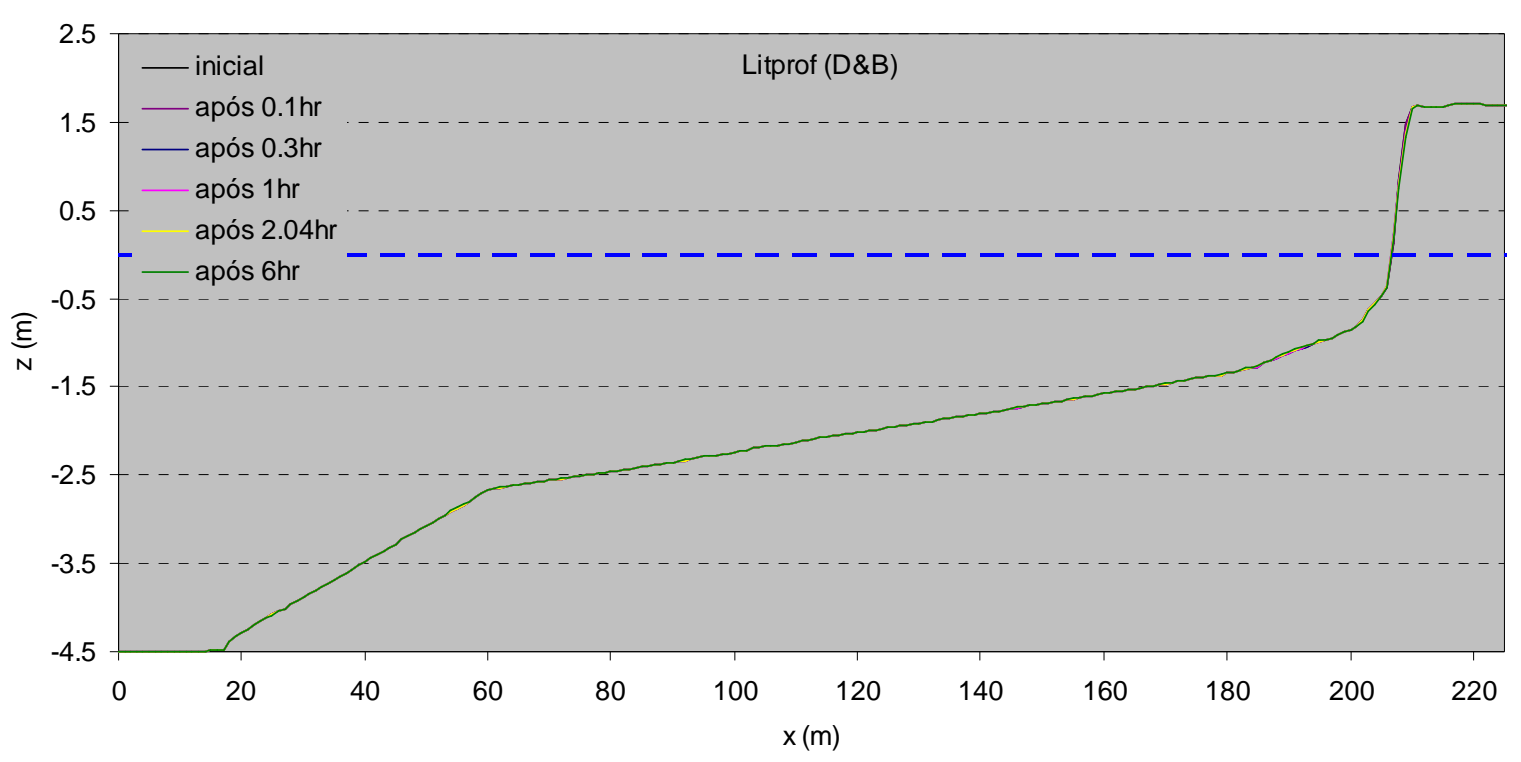

d)

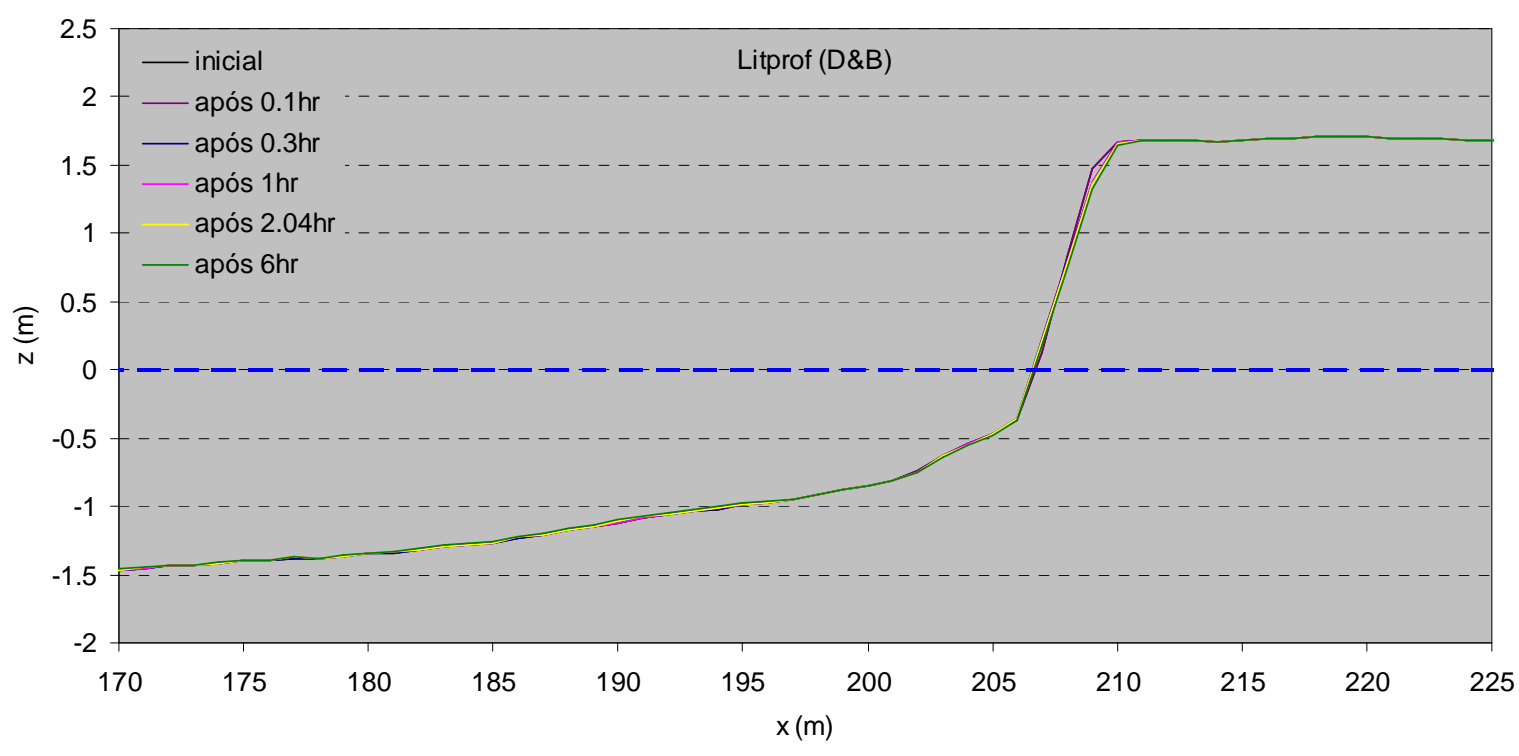

Figura 4 - Resultados numéricos do modelo Litprof para as teorias de onda Stokes5 e D\&B com parâmetros por defeito à escala laboratorial (envelope da evolução): a) e c) perfil completo; b) e d) pormenor da zona activa.

\subsubsection{Comparação}

Compararam-se os modelos XBeach e Litprof, ambos com os parâmetros por defeito, com base nos resultados laboratoriais. As Figuras 5a-e, 6a-c e 7 mostram, respectivamente, os perfis após 0.1, 0.3, 1, 2.04 e 6 horas de simulação (à escala laboratorial), os indicadores de impacto para avaliação do desempenho dos modelos, volume de erosão, recuo da duna (ao nível da água) e recuo do topo da duna, e o indicador de erro para avaliação do desempenho dos modelos, BSS.

Os resultados de evolução do perfil (Figuras 5a-e) indicam que o modelo XBeach sobrestima o recuo do topo da duna numa fase inicial do processo erosivo, até aproximadamente ao final do quarto intervalo de medição do perfil experimental (após 2.04 horas), e posteriormente passa a subestimar este parâmetro até à conclusão da experiência (após 6 horas). 0 modelo XBeach simula o declive da face da duna 
significativamente mais suave do que o declive observado, que é praticamente vertical durante a experiência. Durante o processo erosivo a base da duna não só recua como sobe na vertical. No entanto, o modelo XBeach não reproduz com exactidão o deslocamento vertical da base da duna. Observa-se que o modelo não reproduz subida da base da duna a partir do nível da água (z igual a zero), o que evidencia falta de realismo na formulação matemática do processo de avalanche. Relativamente à evolução da parte submersa do perfil observa-se que o modelo XBeach tende a aproximar o declive do perfil submerso do declive observado durante a experiência. Contudo, observa-se que o modelo não reproduz a barra submersa que se observa para valores de x entre 185 e $192 \mathrm{~m}$. Observa-se ainda que 0 modelo subestima a extensão da zona de acumulação da areia transportada da face da duna, no entanto, tal dever-se-á ao facto do volume de erosão ser ligeiramente subestimado pelo modelo.

Ao primeiro intervalo de medição do perfil experimental (após 0.1 hora) o indicador de impacto volume de erosão simulado com o modelo XBeach e observado é praticamente igual. Com o decorrer da experiência, o modelo passa a subestimar o volume de erosão e a diferença entre o valor observado e numérico cresce (Figura 6a). No final da experiencia o volume de erosão simulado é aproximadamente $75 \%$ do volume observado. Os indicadores de impacto recuo da duna (ao nível da água) e recuo do topo da duna evidenciam que a taxa de recuo da base da duna é semelhante à taxa de recuo do topo da duna e que tal não se verifica nos resultados numéricos (Figuras $6 b-c$ ). A falta de concordância entre os resultados numéricos e experimentais do indicador recuo da duna, que é significativamente maior do que a falta de concordância entre os resultados numéricos e experimentais do indicador recuo do topo da duna, deve-se ao facto do modelo não reproduzir correctamente o processo de avalanche, conforme já referido. A evolução do indicador de erro BSS mostra que o desempenho do modelo XBeach melhora ao longo da experiência (Figura 7).

A comparação da evolução do perfil experimental com a evolução dos perfis numéricos obtidos com modelo Litprof para ambas as teorias de onda demonstra que o modelo com os parâmetros por defeito não simula o processo de erosão da duna. Considera-se por isso que dos modelos Xbeach e Litprof aquele com melhor desempenho com os parâmetros por defeito é o modelo XBeach.

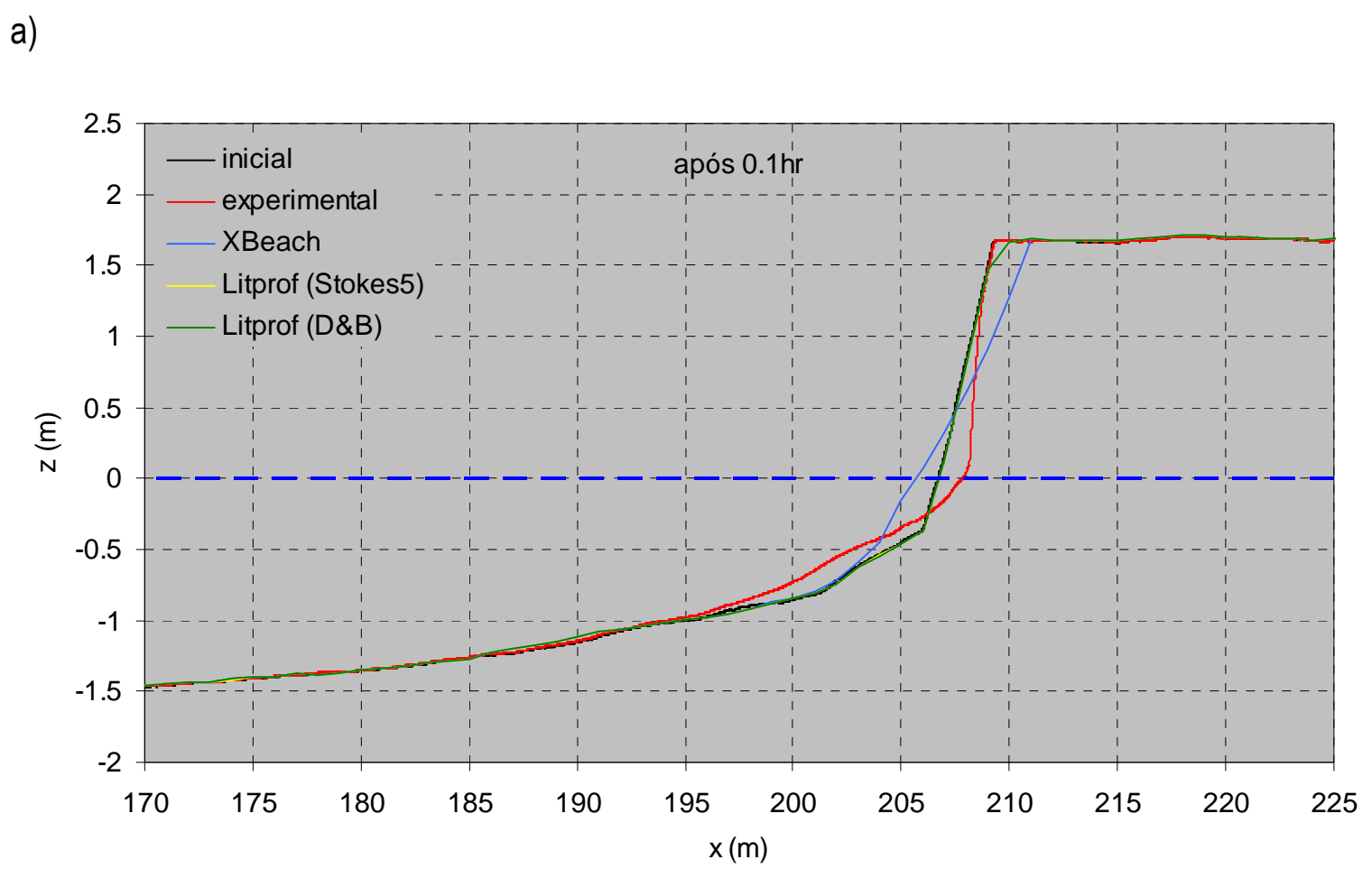


b)

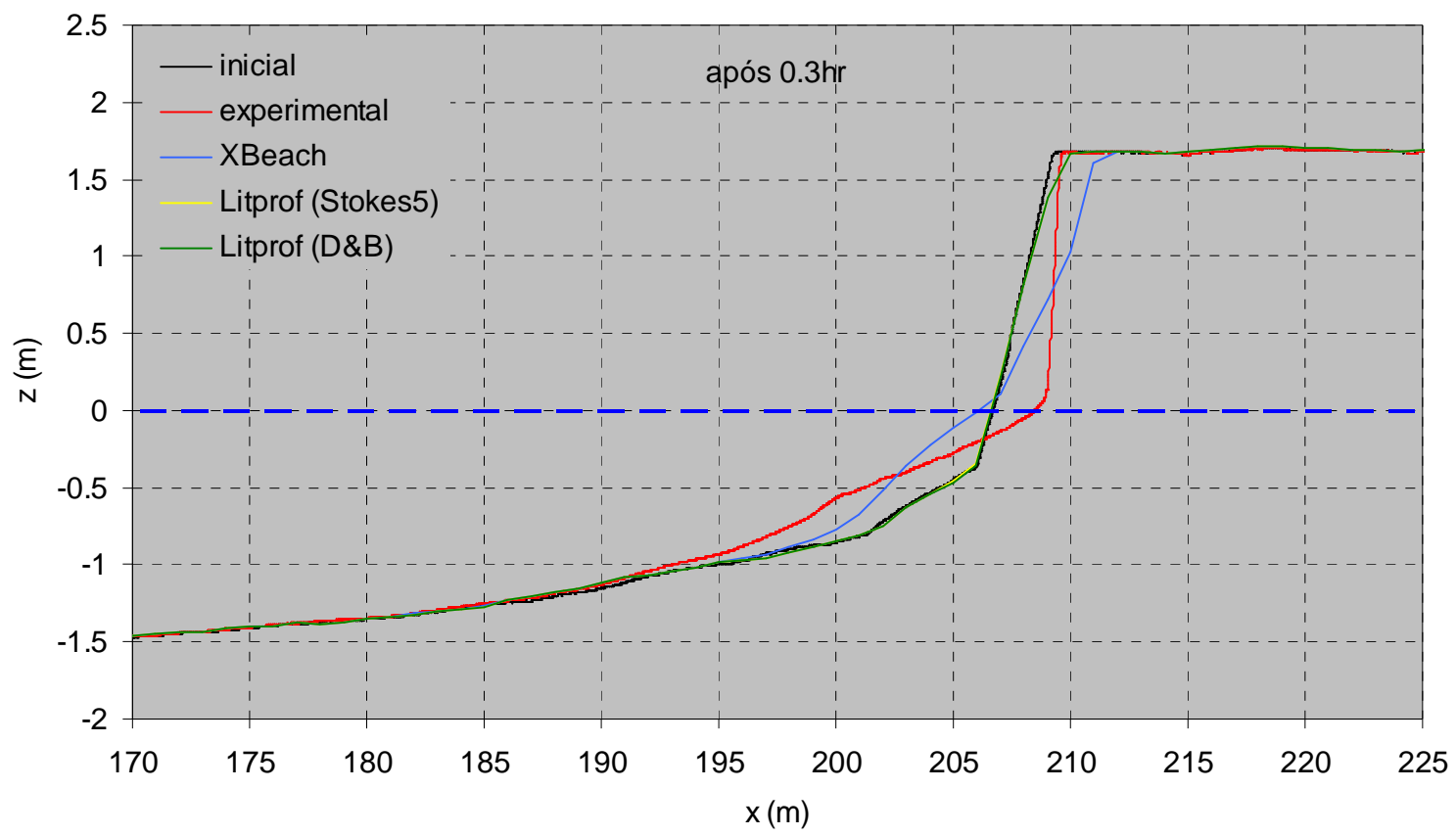

c)

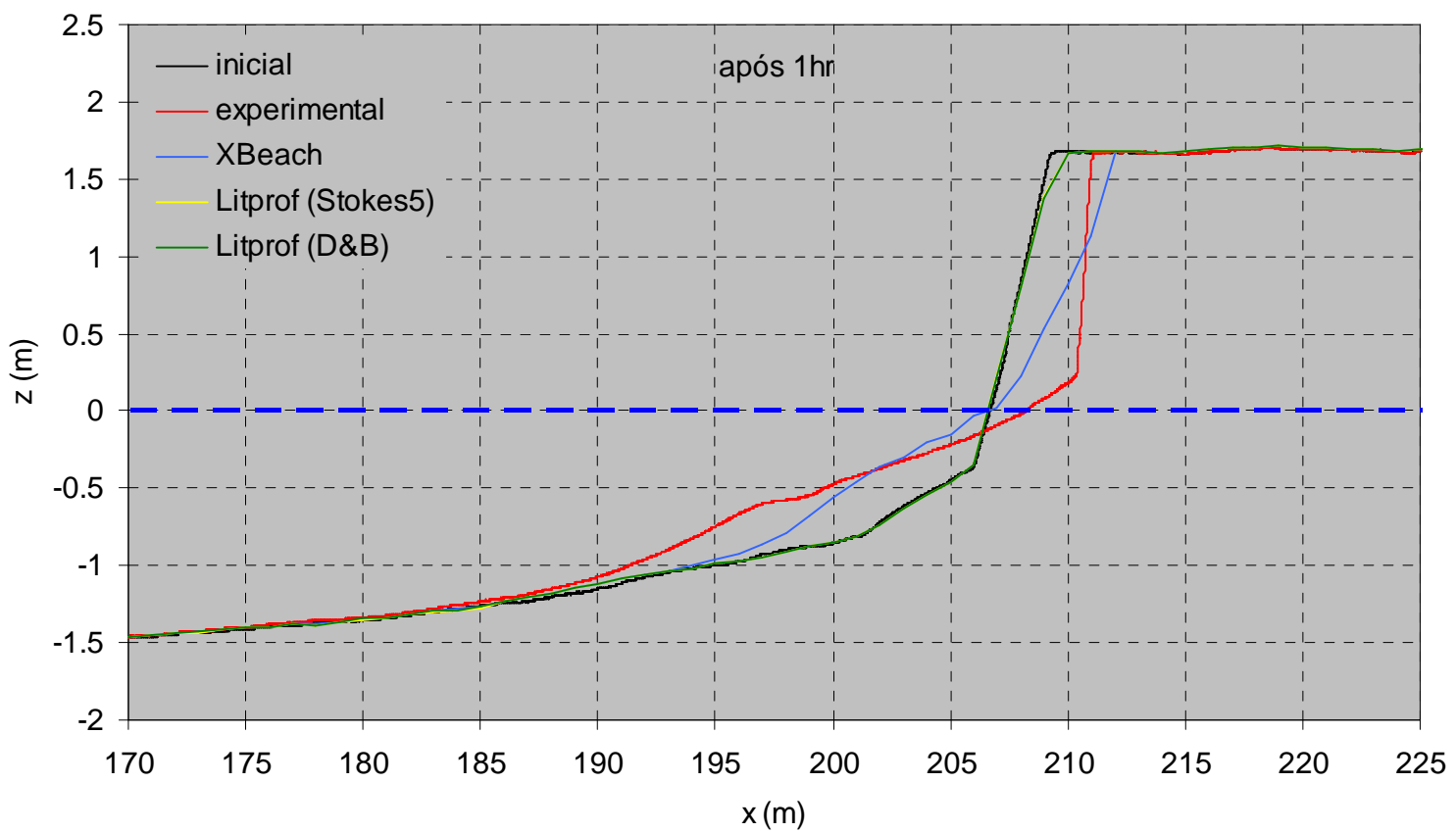


d)

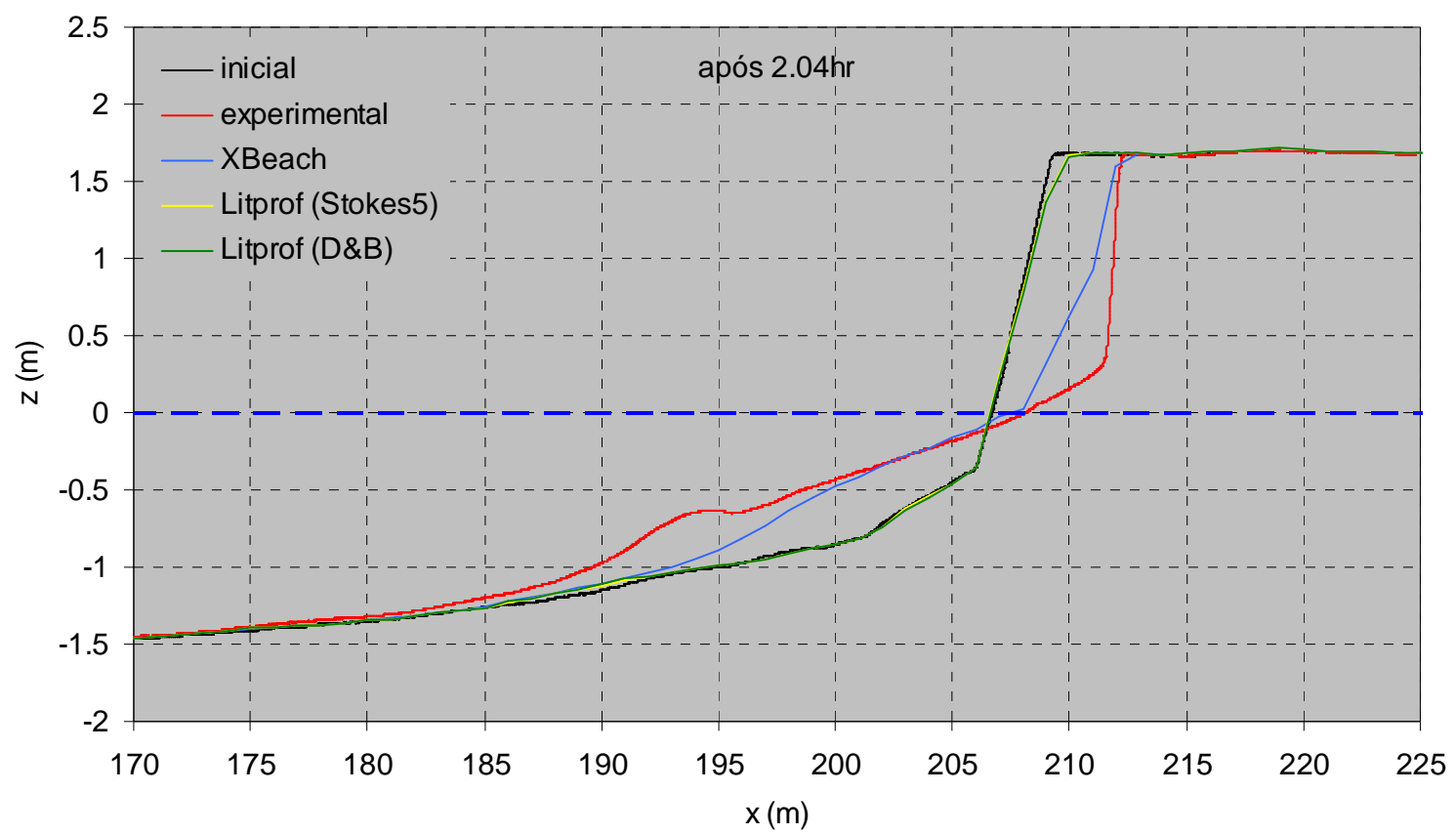

e)

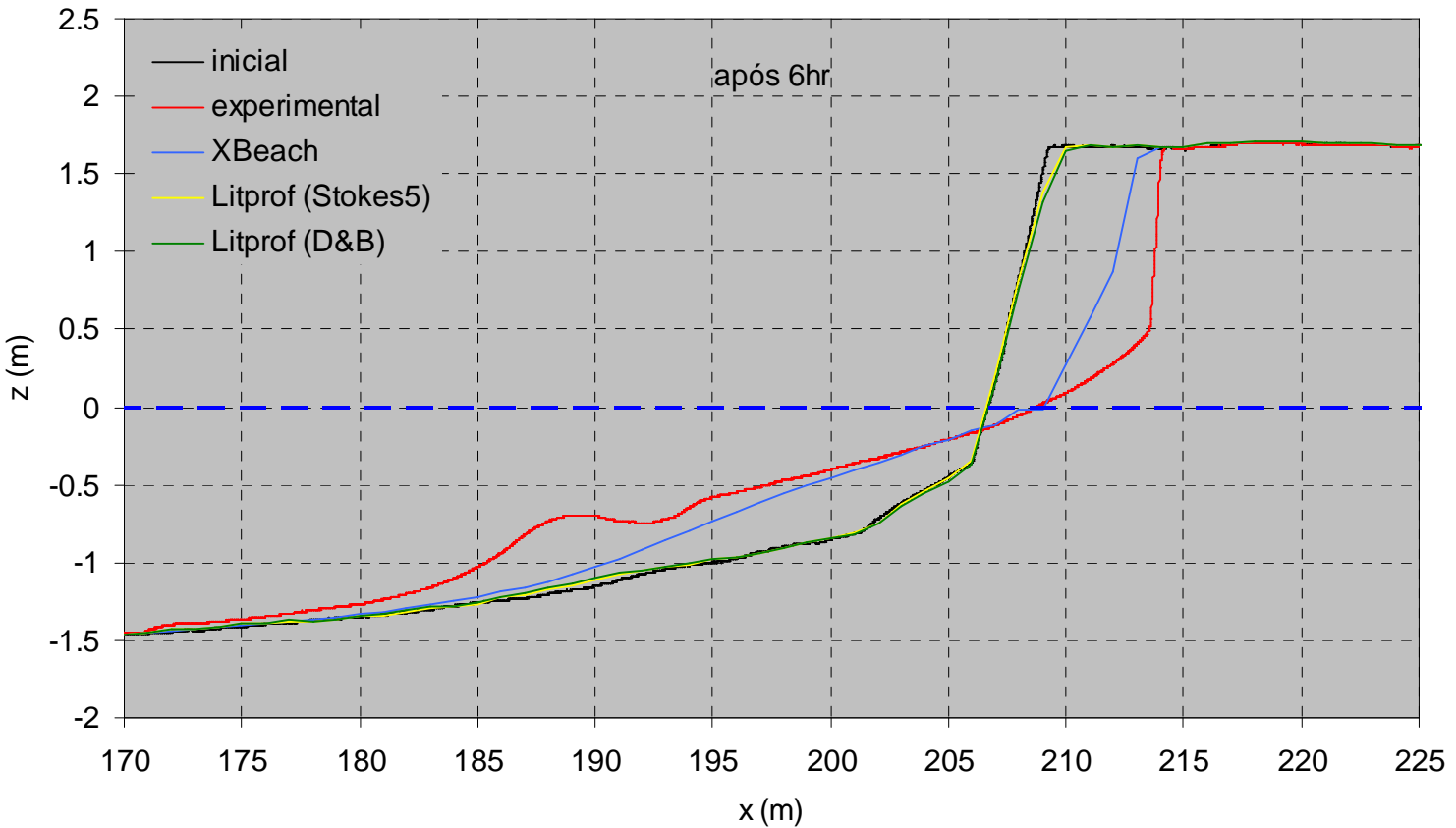

Figura 5 - Resultados numéricos dos modelos XBeach e Litprof (para as teorias de onda Stokes 5 e D\&B) com parâmetros por defeitos, à escala laboratorial, ao final de $0.1,0.3,2.04$ e 6 horas. A linha a azul representa a previsão XBeach, a linha amarelo representa a previsão Litprof-Stokes5, a linha verde representa a previsão Litprof-D\&B, a linha vermelha representa o perfil experimental e a linha preta representa o perfil inicial. 
a)

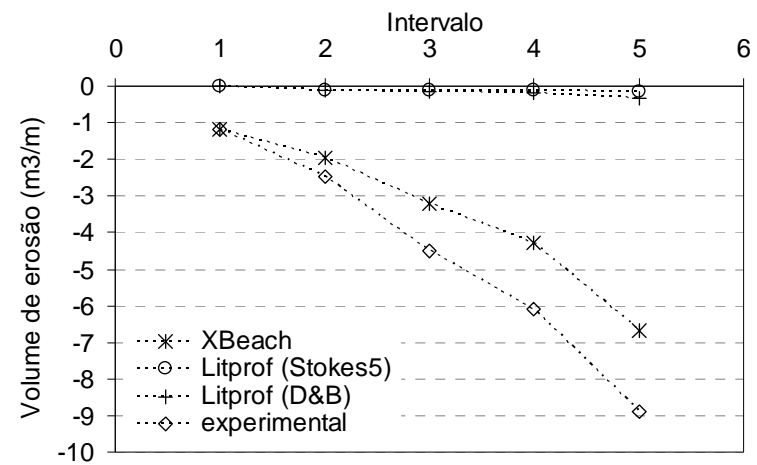

b)

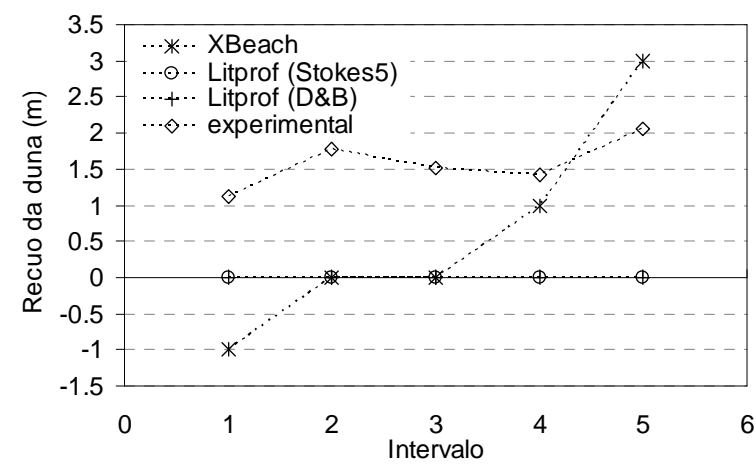

c)

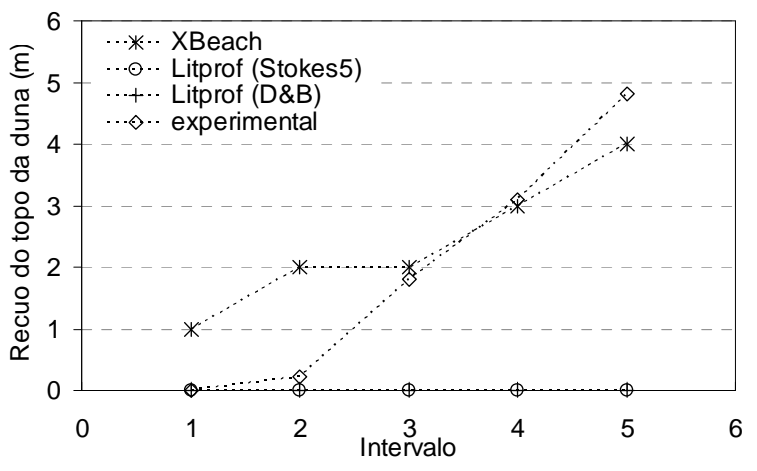

Figura 6 - Indicadores de impacto para os modelos XBeach e Litprof (para as teorias de onda Stokes5 e D\&B) com parâmetros por defeito: a) Volume de erosão, b) Recuo da duna e c) Recuo do topo da duna.

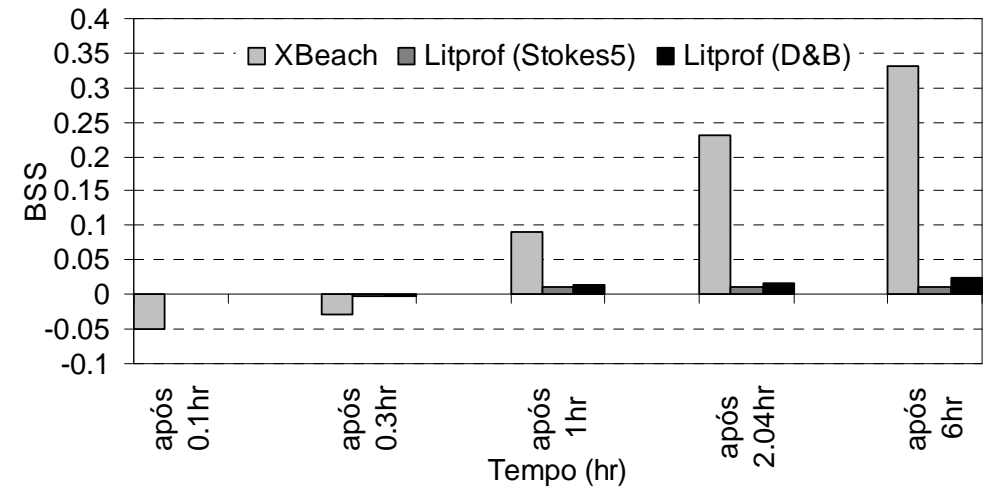

Figura 7 - Indicador de erro BSS para os modelos XBeach e Litprof (para as teorias de onda Stokes5 e D\&B) com parâmetros por defeito.

\subsection{Calibração}

Testaram-se os parâmetros de calibração para cada um dos modelos, tendo como base os parâmetros por defeito. Neste processo, fez-se variar um parâmetro de cada vez mantendo os outros constantes. Apresentam-se os resultados dos testes efectuados. Posteriormente faz-se a avaliação do desempenho dos modelos XBeach e Litprof com base na comparação dos dois modelos para os melhores resultados obtidos após calibração. 


\subsubsection{Modelo XBeach}

A identificação dos parâmetros de calibração no modelo XBeach é um tema bastante importante, do qual depende o desempenho do modelo. No entanto, verifica-se que ainda não existe suficiente experiência sobre a aplicação do modelo de forma a apontar com clareza quais os parâmetros, de entre um grande número, a testar. Também por isso, a realização deste estudo é de grande importância.

Para identificar os parâmetros de calibração procurou-se numa primeira fase seleccionar os parâmetros considerados em casos anteriores de aplicação do modelo. Roelvink et al. (2009) relatam o maior número de casos de aplicação do modelo conhecidos, no entanto, não esclarecem sobre o processo de calibração. Das aplicações do modelo publicadas, a que descreve uma análise sobre alguns dos parâmetros de calibração utilizados é a de Vousdoukas et al. (2011), para um caso real de praia reflectiva. Os autores salientam que os parâmetros com maior resposta morfológica foram Iws, facua e wets/p. Numa outra aplicação, Branderburg (2010), sem detalhar sobre o processo de calibração, recomenda parâmetros de calibração do modelo XBeach quando aplicado em modelos experimentais de pequena escala. $O$ autor recomenda o teste aos parâmetros hmin, eps, turb, morfac, wets/p, hswitch, dzmax e Tsmin. Num outro caso de erosão dunar (testado pela autora, mas não publicado), o modelo mostrou-se sensivel aos parâmetros drys/p, Iws e hswitch.

Neste estudo, tendo em conta os trabalhos acima mencionados e após analisada pormenorizadamente a formulação do modelo e respectivos parâmetros (recomenda-se a análise de Roelvink et al., 2010), testaram-se os parâmetros: beta, break, facsl, facua, gammax, hmin, hswitch, Iws, turb, wetsl, dryslp e order. Testou-se o modelo para os valores: 0.2 de beta, 1,2 e 4 de break, 0.8 de facsl, 1 de facua, 0.5 de gammax, 0.001 de hmin, 0.01 e 1 de hswitch, 1 de Iws, 0 e 1 de turb e 0.15, 0.6 de wets/p, 2 de drys/p e 2 de order. Fez-se variar cada um destes parâmetros de cada vez relativamente à situação default (com os parâmetros por defeito).

Os resultados numéricos ao final de 6 horas (Figuras 8a-I) mostram que os parâmetros mais influentes na evolução morfológica para este caso de estudo são beta, break, facua, gammax, hswitch, Iws e wets/p. Os parâmetros facsl, hmin, turb, drys/p e order influenciaram muito pouco os resultados obtidos com os parâmetros por defeito. Dos parâmetros mais influentes na evolução da geometria do perfil, os parâmetros Iws e wets/p foram aqueles que conferiram ao perfil final uma geometria mais próxima da configuração observada (Figuras $8 \mathrm{~h}$ e 8j, respectivamente). Os resultados obtidos para 0 indicador de erro BSS (Figura 9) evidenciam que o melhor desempenho, classificado como excelente (de acordo com a Tabela 1), foi obtido com alteração do parâmetro Iws de 0 (por defeito) para 1 e que o segundo melhor desempenho foi obtido com a alteração do parâmetro wets/p de (0.3) para 0.15. Uma vez que a alteração morfológica alcançada com a modificação do parâmetro Iws permitiu melhorar a previsão das duas características fundamentais sob o ponto de vista da engenharia que são o recuo do topo da duna e 0 limite da extensão da zona activa (onde se observou a formação da barra submersa durante a experiência), considera-se que este parâmetro é de grande relevância na simulação da evolução da erosão de dunas com o modelo XBeach. 
a)
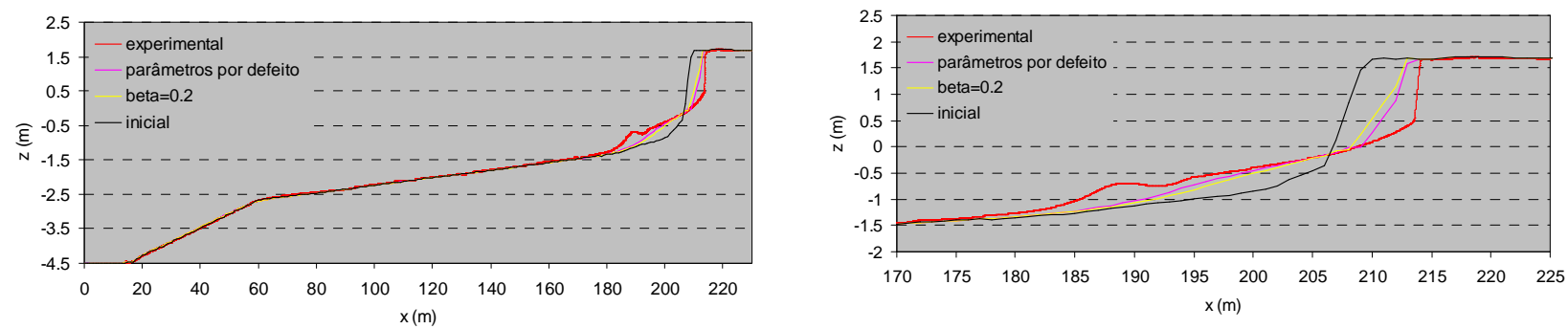

b)
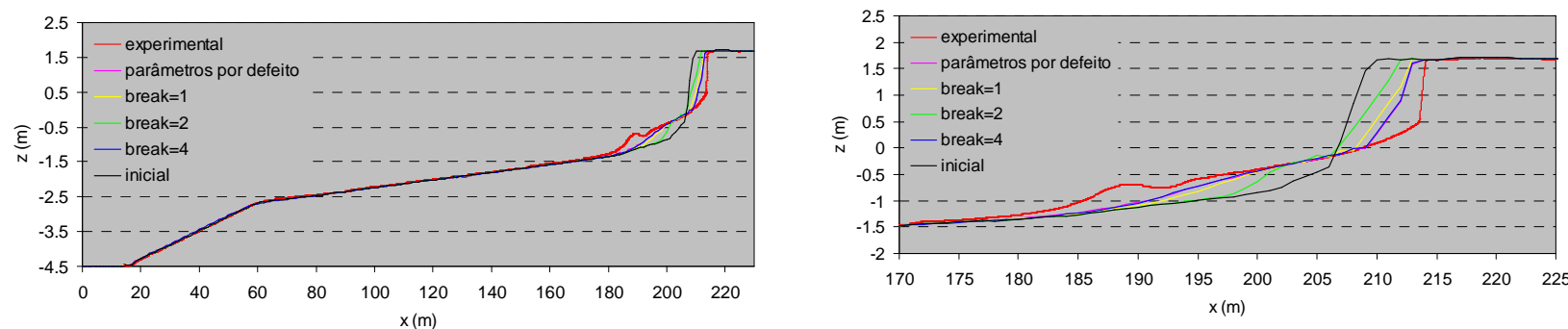

c)
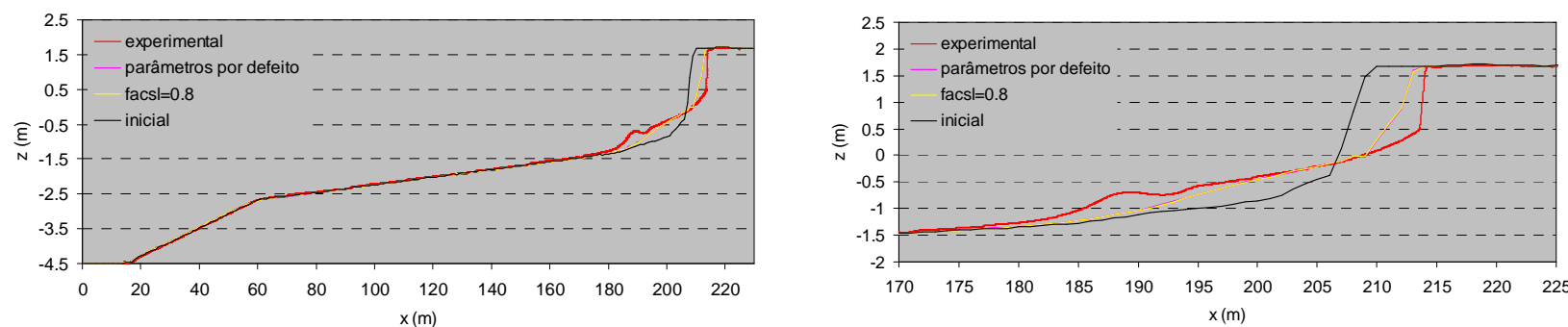

d)
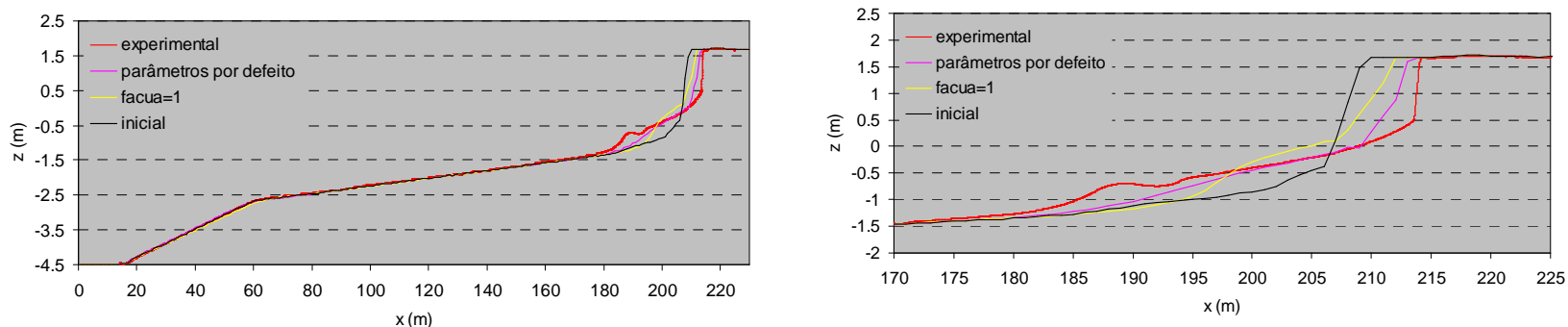

e)
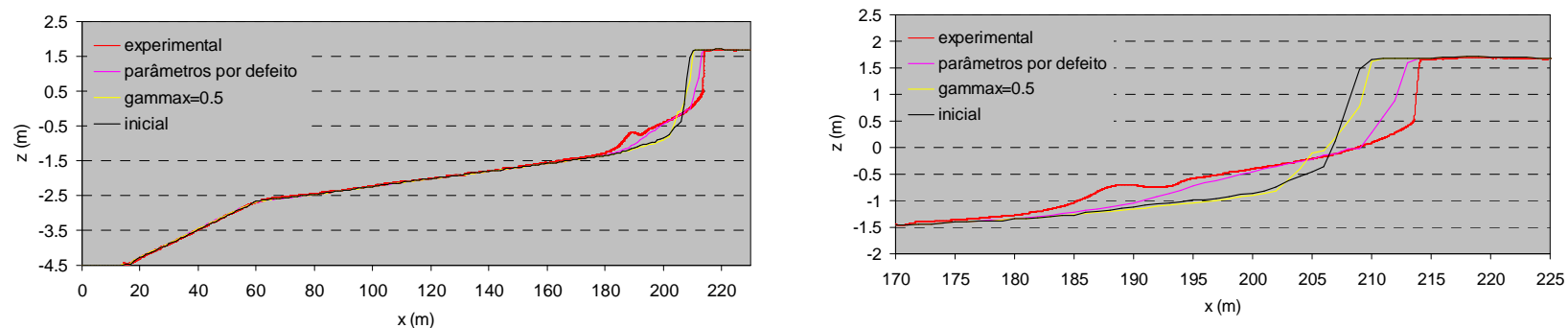
f)
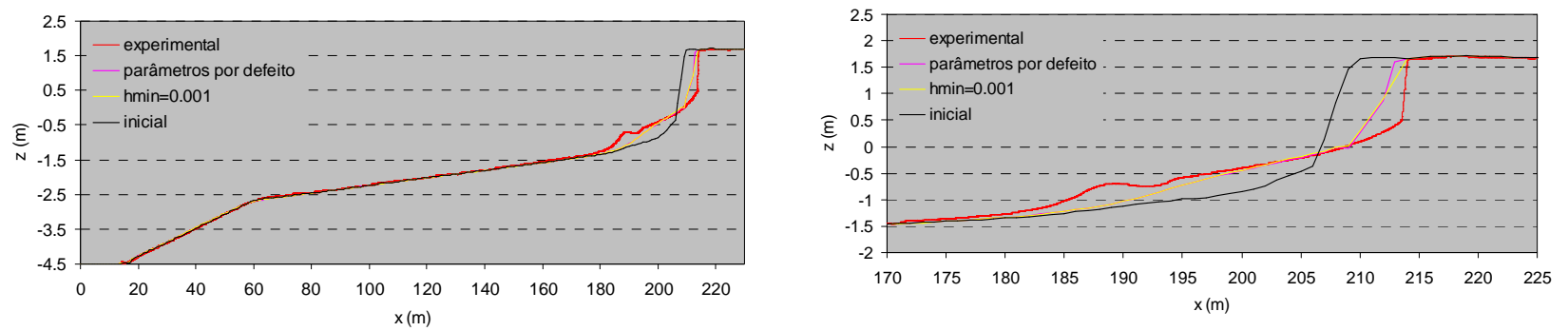

g)
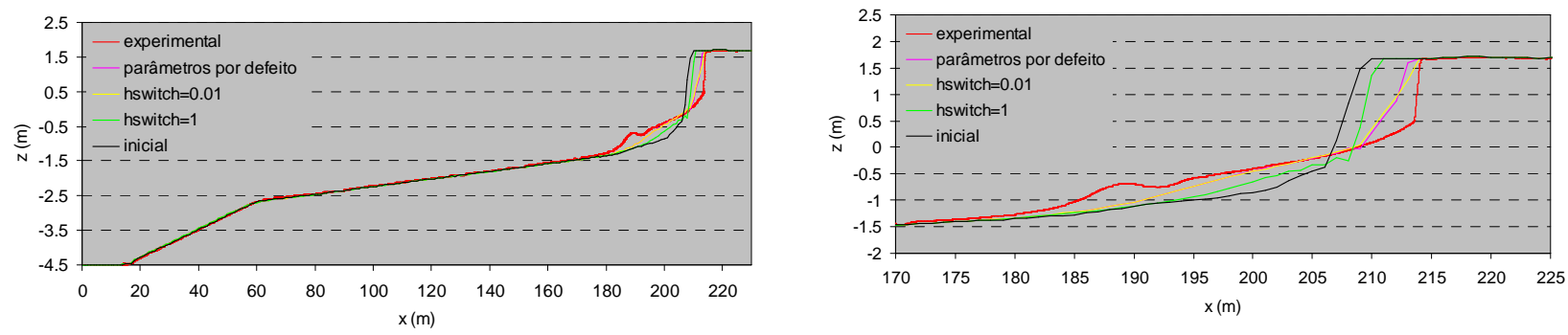

h)
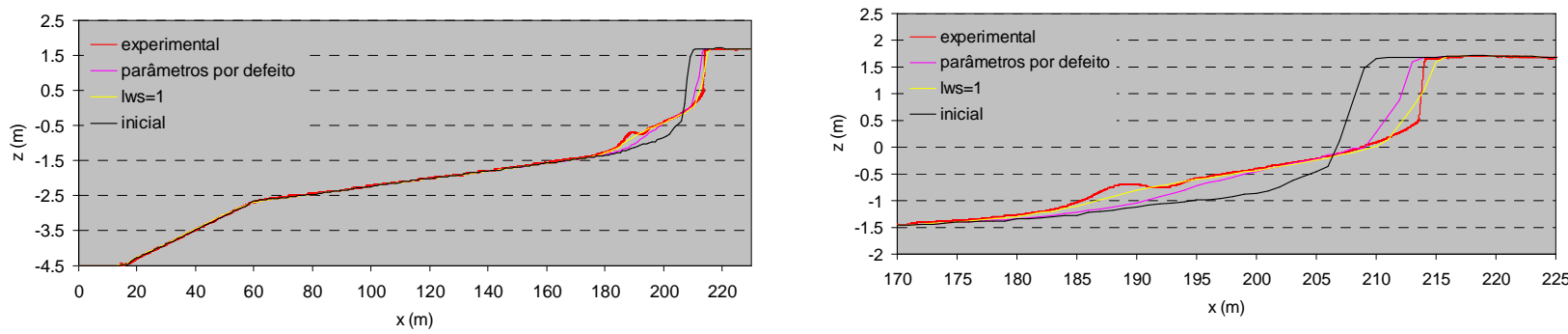

i)
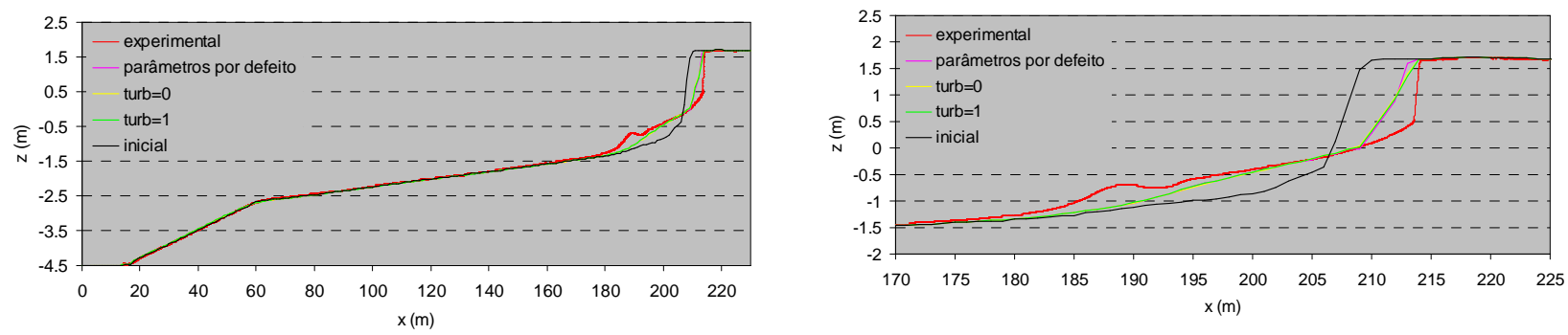

j)
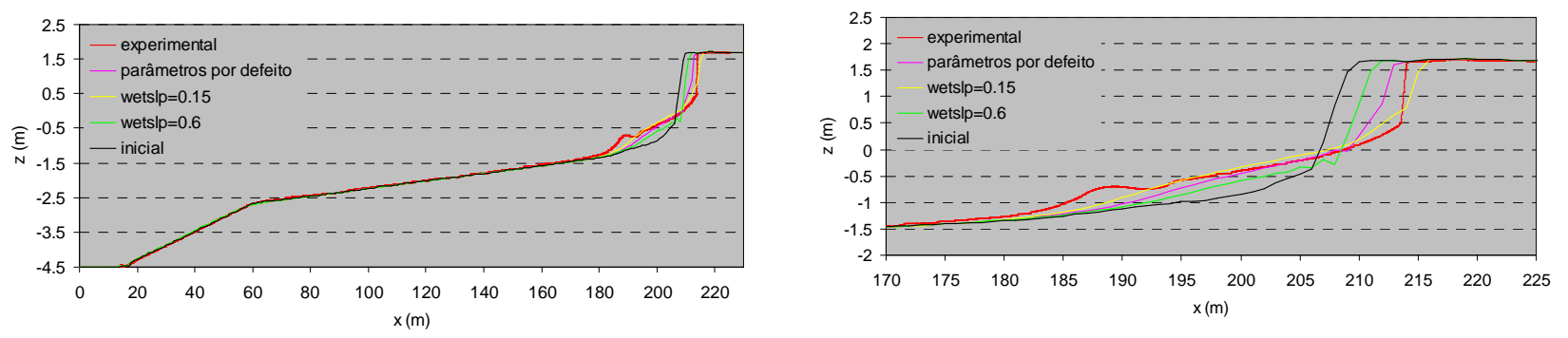
k)
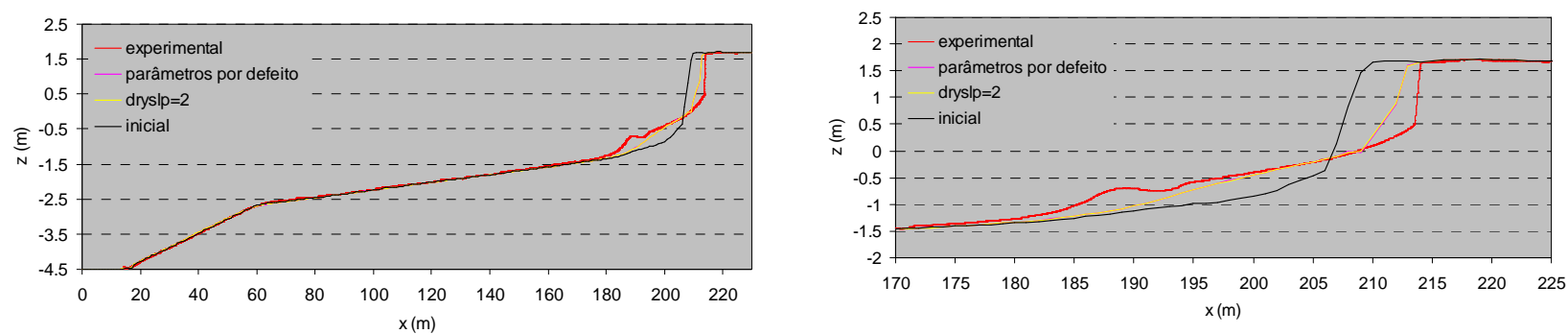

l)
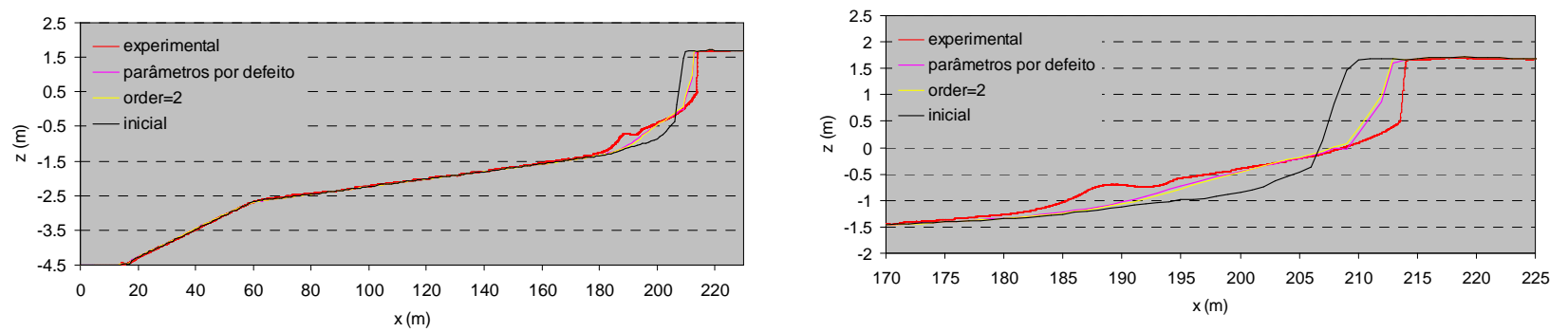

Figura 8 - Resultados numéricos do modelo XBeach, à escala laboratorial, ao final 6 horas. Teste aos parâmetros de calibração a) beta, b) break, c) facsl, d) facua, e) gammax, f) hmin, g) hswitch, h) Iws, i) turb, j) wets(p, k) dryslp e I) order.

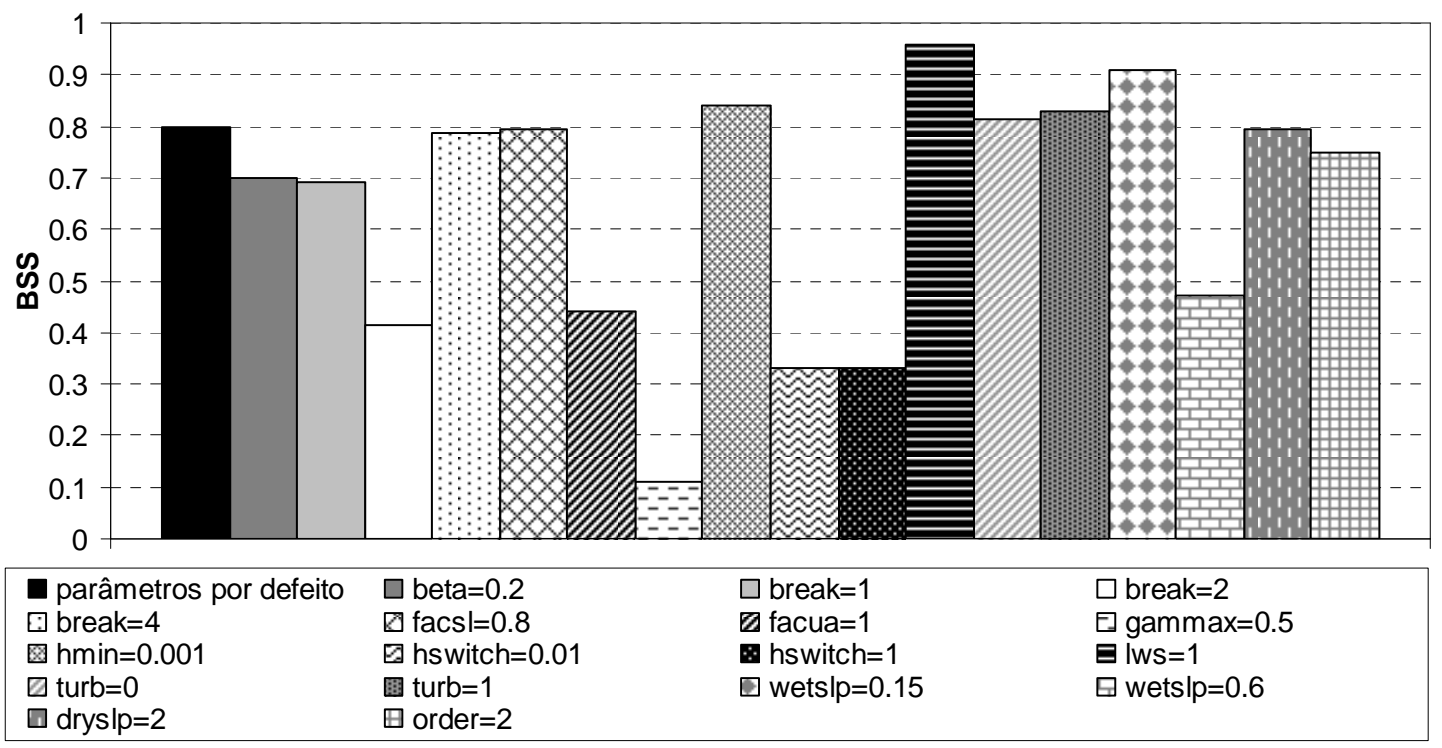

Figura 9 - Indicador de erro BSS para os testes de calibração do modelo XBeach.

\subsubsection{Modelo Litprof}

Neste modelo, os principais parâmetros de calibração são os parâmetros de rebentação da onda e o parâmetro de escala. Da comparação dos parâmetros por defeito comuns aos dois modelos, verificou-se que o modelo XBeach é menos tolerante no que respeita ao máximo declive de fundo para cálculo da avalanche submersa. XBeach considera o declive crítico de avalanche submersa (wets/p) igual 0.3 (Tabela 2) e o modelo Litprof considera o máximo ângulo de fundo submerso igual a $30^{\circ}$ (Tabela 3), que corresponde ao valor 0.6 do parâmetro wets/p do modelo XBeach. Assim, testaram-se: os parâmetro de 
rebentação $\gamma_{1}$ e $\gamma_{2}$, o parâmetro de escala $\alpha_{\text {scale }}$ e o máximo ângulo de fundo submerso estável (Maximum Angle of Bed Slope). Os parâmetros $\gamma_{1}$ e $\gamma_{2}$ são considerados na estimativa da máxima altura de onda, $H_{\max }$, que por sua vez é necessária para estimar a energia dissipada segundo Battjes e Janssen (1978). Eles são considerados na formulação seguinte

$$
H_{\text {max }}=\frac{\gamma_{1}}{\gamma_{2}} \tanh \left(\frac{\gamma_{2} k h}{\gamma_{1}}\right)
$$

onde $k$ é o número de onda e $h$ a profundidade. 0 parâmetro de rebentação $\gamma_{1}$ descreve a máxima declividade da onda, $H / L$. O parâmetro de rebentação $\gamma_{2}$ é, segundo Battjes e Stive (1984) calculado da seguinte forma

$$
\gamma_{2}=0.5+0.4 \tanh \left(33 s_{0}\right)
$$

onde $s_{0}$ é o declive de onda ao largo, $H / L_{0}$, e $L_{0}$ é o comprimento de onda ao largo. $O$ parâmetro $\alpha_{\text {scale }}$ é um coeficiente de difusão horizontal que afecta a forma de desenvolvimento das barras (DHI, 2008). Fez-se variar cada um destes parâmetros de cada vez relativamente à situação default (com os parâmetros por defeito). Testou-se o modelo para os valores: 0.75 e 0.95 de $\gamma_{1}, 0.8,0.9$ e 1.5 de $\gamma_{2}, 0.8$ e 1.2 de $\alpha_{\text {scale }}$, e 10 e $20^{\circ}$ de Maximum Angle of Bed Slope.

Os resultados numéricos ao final de 6 horas mostram que a variação dos parâmetros $\gamma_{1}, \gamma_{2}$ e $\alpha_{\text {scale }}$ não causa qualquer alteração relevante na evolução morfológica do perfil, à semelhança dos resultados obtidos com os parâmetros por defeito, para ambas as teorias de onda aplicadas (Figura 10a-c). 0 indicador de erro BSS para os testes de calibração do modelo Litprof para as duas teorias de onda podem ser vistos na Figura 12a-c. A diminuição do máximo ângulo de fundo antes de avalanche submersa (Maximum Angle of Bed Slope) causa erosão da face da duna (Figura 10d), pois limitando 0 máximo declive de fundo é acelerado o processo de instabilidade e consequente erosão na zona da base da duna. Contudo, a geometria da duna não é correctamente reproduzida. Apesar do recuo do topo da duna estimado ser muito próximo do observado, o declive da face é bastante mais suave do que 0 declive observado o que faz com que o modelo Litprof reproduza avanço da duna ao nível da água (para $z$ igual a zero) enquanto no perfil experimental se observa recuo. 0 indicador de erro BSS para os testes de calibração do modelo Litprof com este parâmetro, para as duas teorias de onda, pode ser visto na Figura 12d. Concluiu-se que a falta de similaridade entre os resultados numéricos obtidos com o modelo Litprof e os resultados experimentais deve-se ao facto do modelo não abordar correctamente o processo de avalanche em zona seca nem considerar a acção de ondas longas.

Dados os resultados obtidos nos testes de calibração, testou-se ainda o modelo à variação dos parâmetros $\gamma_{2}$ e Maximum Angle of Bed Slope combinados, na expectativa de que a alteração do perfil alcançada através da deposição da areia erodida da face da duna (à custa da redução do Maximum Angle of Bed Slope para $10^{\circ}$ ) causasse um aumento do transporte para maiores profundidades no caso de se fazer variar o parâmetro $\gamma_{2}$ (máxima razão entre a altura de onda e a profundidade, $H / h$ ). Por isso, realizaram-se mais dois testes do modelo Litprof, considerando o valor de Maximum Angle of Bed Slope igual a $10^{\circ}$ e os valores de $\gamma_{2}$ iguais a 0.9 e 1.5. Para $\gamma_{2}$ igual a 0.9 não se verifica melhoria do resultado (Figura 11), provavelmente porque a extensão da zona de acumulação do volume extraído da face da duna é insuficiente para causar alteração da posição de rebentação das ondas e aumentar o transporte para maiores profundidades por acção da corrente de retorno. No entanto, para $\gamma_{2}$ igual a 1.5 verifica-se que aumenta ligeiramente o volume de areia extraído da face da duna e que a acumulação deste na parte submersa do perfil estende-se até maiores profundidades com tendência para formação de uma barra pouco pronunciada. O indicador de erro BSS para estes testes é apresentado na Figura 13. 
Concluiu-se que o parâmetro Maximum Angle of Bed Slope foi o mais eficaz na calibração do modelo Litprof e que a teoria de onda não é relevante na evolução do perfil para este caso de estudo. 0 melhor desempenho do modelo Litprof foi alcançado para a alteração dos parâmetros por defeito resultante da combinação do parâmetro Maximum Angle of Bed Slope igual a $10^{\circ}$ com o parâmetro $\gamma_{2}$ igual a 1.5 .

a)

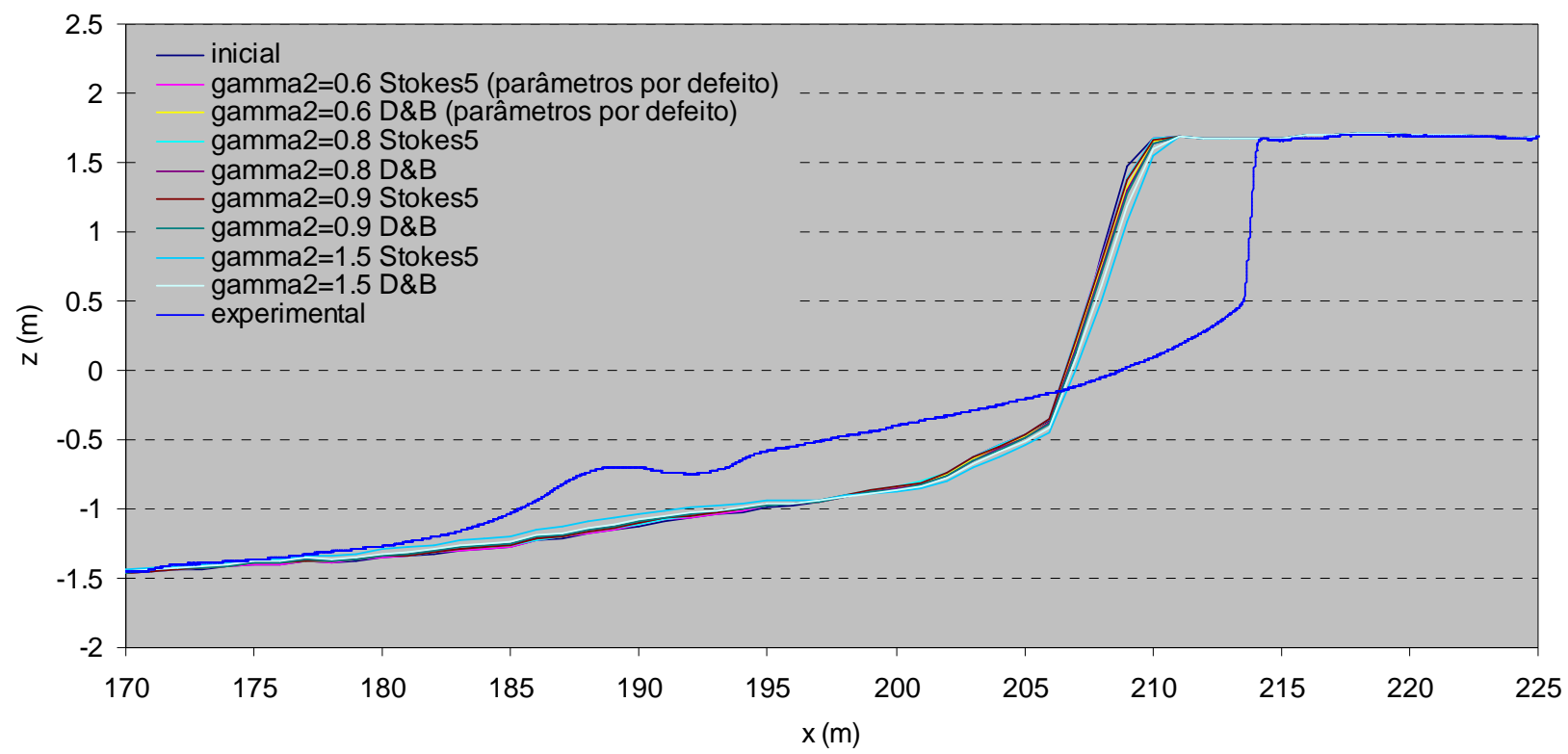

b)

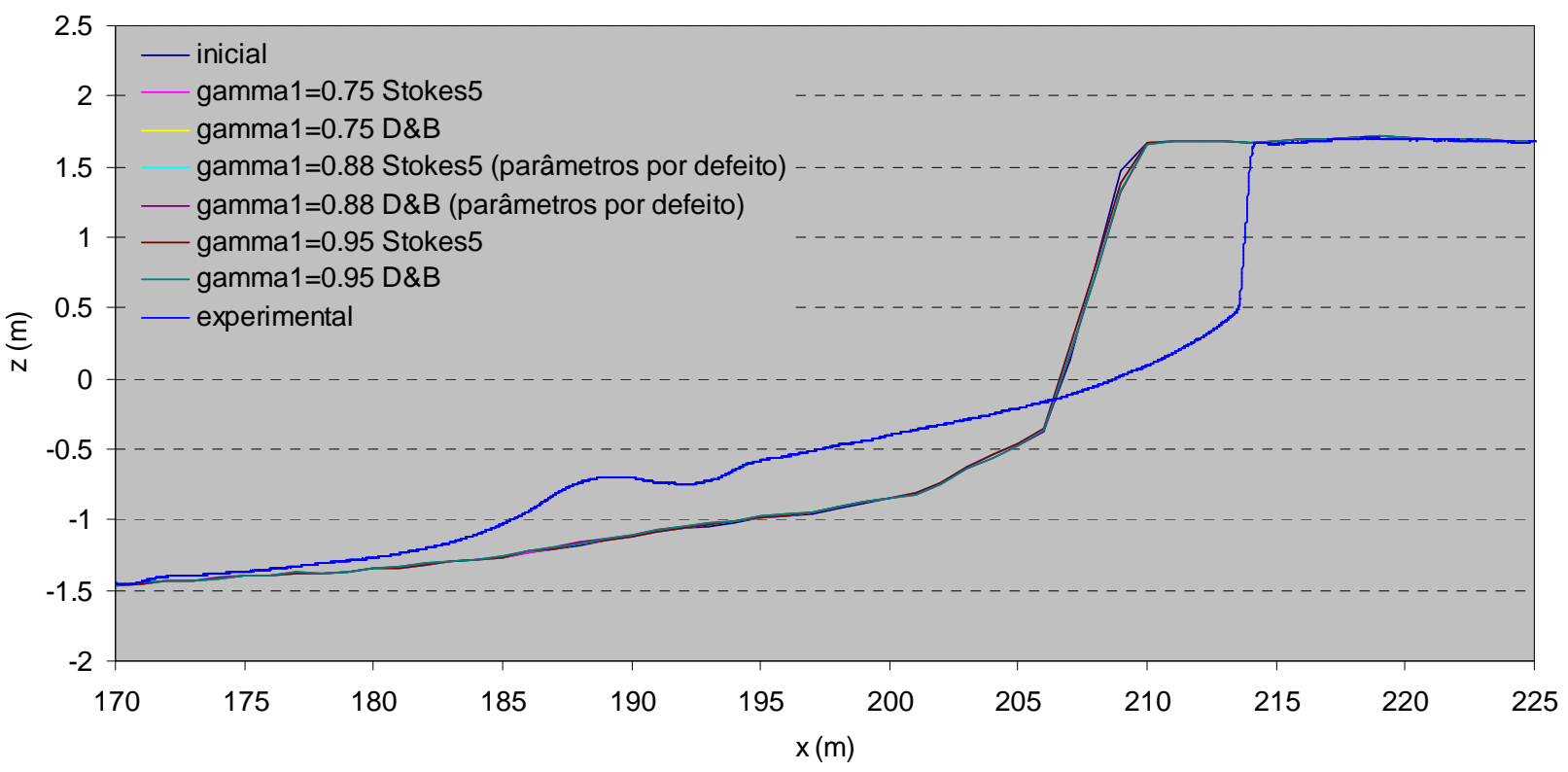


c)

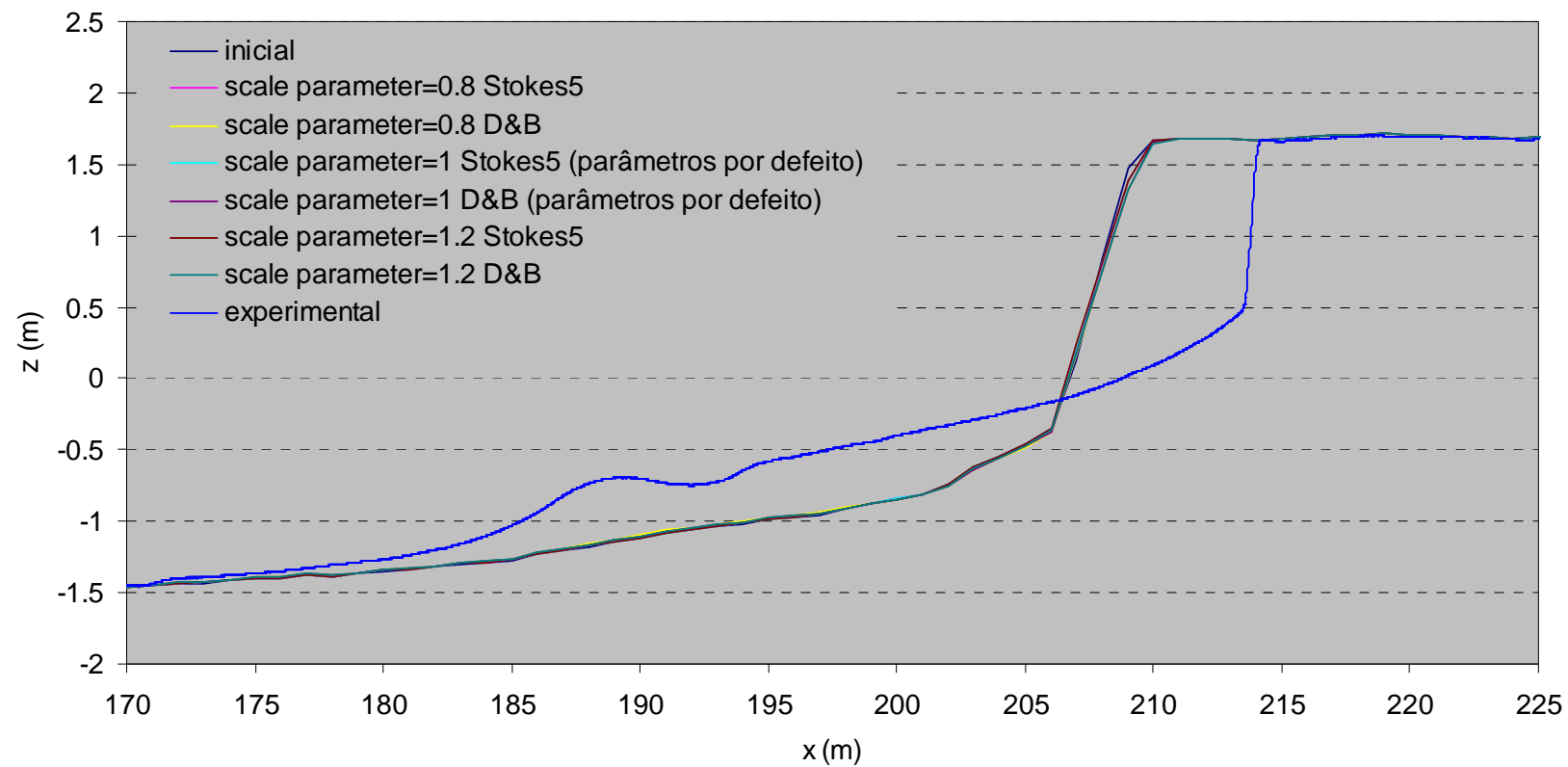

d)

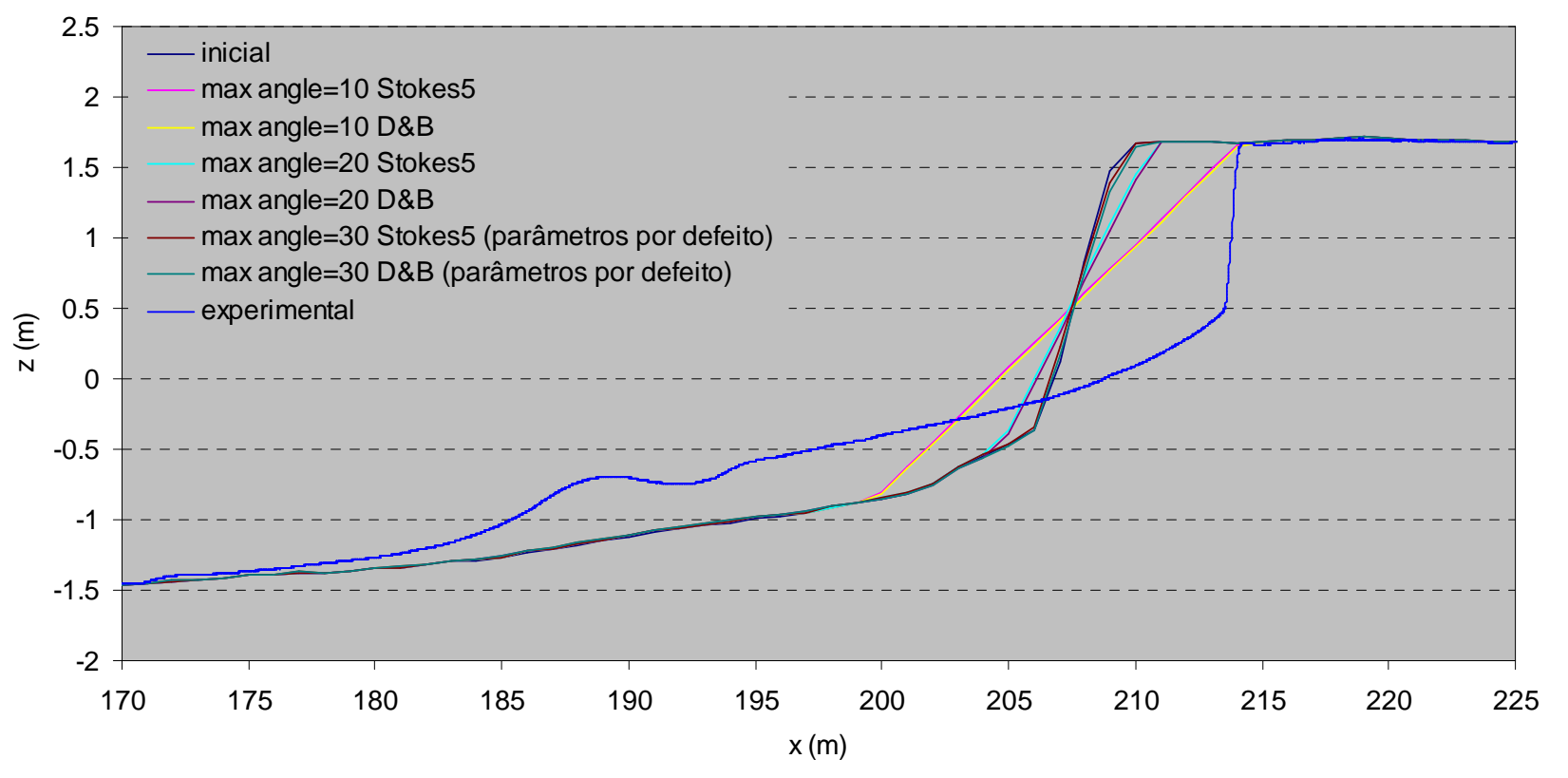

Figura 10 - Resultados numéricos do modelo Litprof (para as teorias de onda Stokes 5 e D\&B), à escala laboratorial, ao final 6 horas. Teste aos parâmetros de calibração a) $\gamma_{1}$, b) $\gamma_{2}$, c) $\alpha_{\text {scale }}$ e d) Maximum Angle of Bed Slope. 


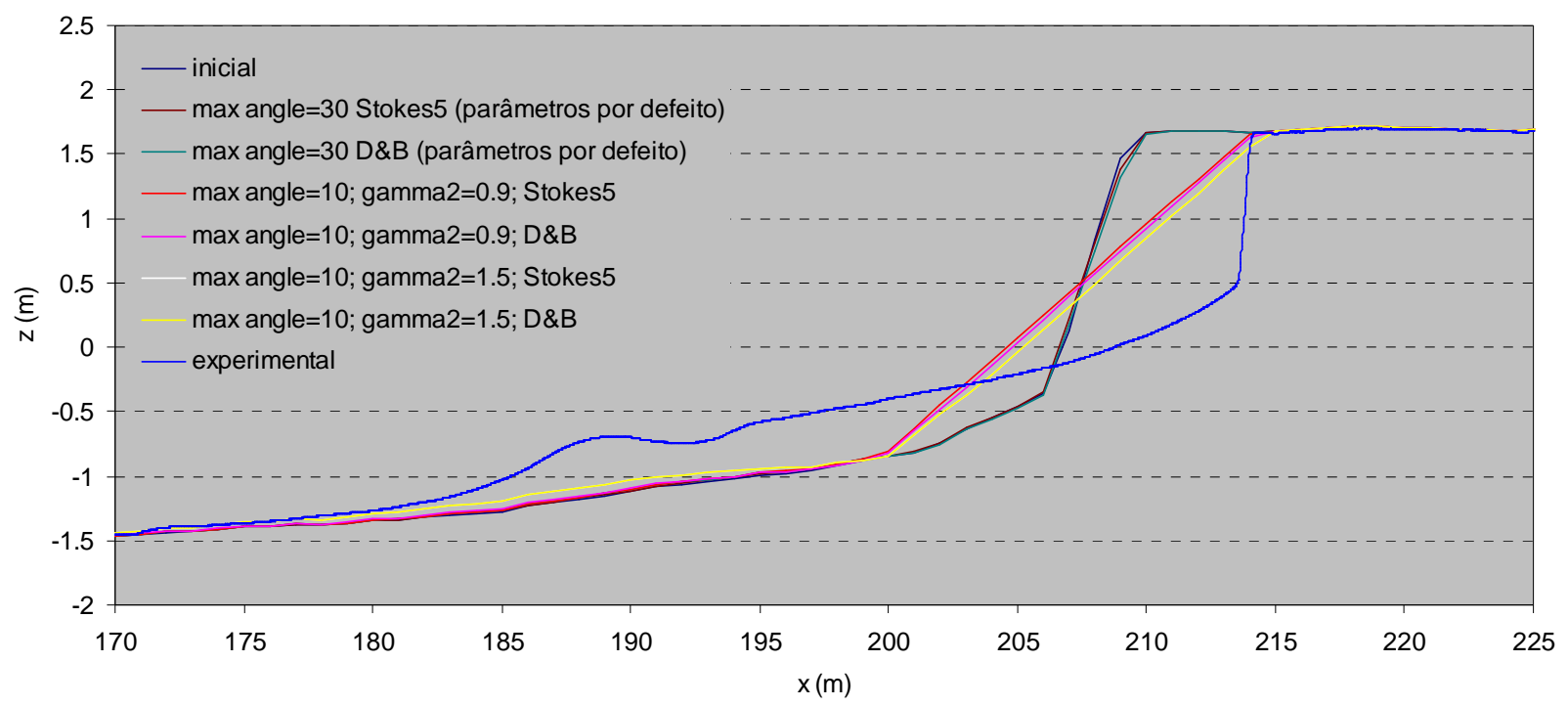

Figura 11 - Resultados numéricos do modelo Litprof (para as teorias de onda Stokes5 e D\&B), à escala laboratorial, ao final 6 horas. Teste aos parâmetros de calibração $\gamma_{2}$ e Maximum Angle of Bed Slope combinados.

a)

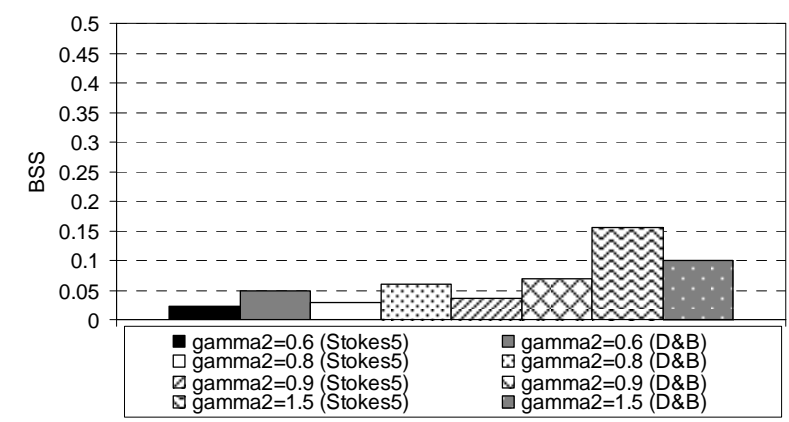

c)

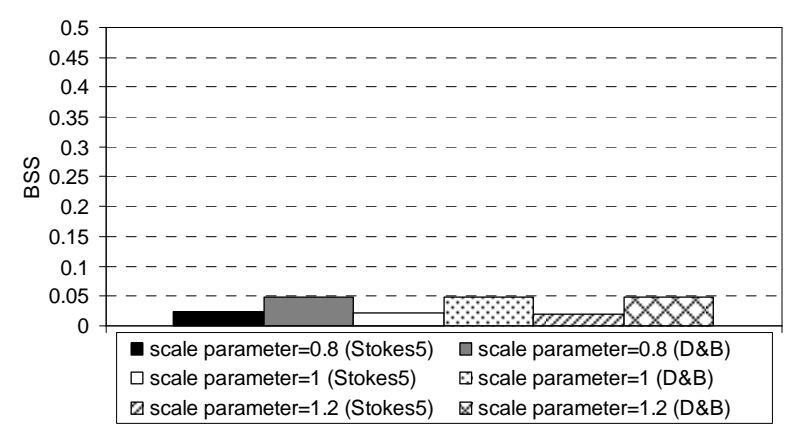

b)

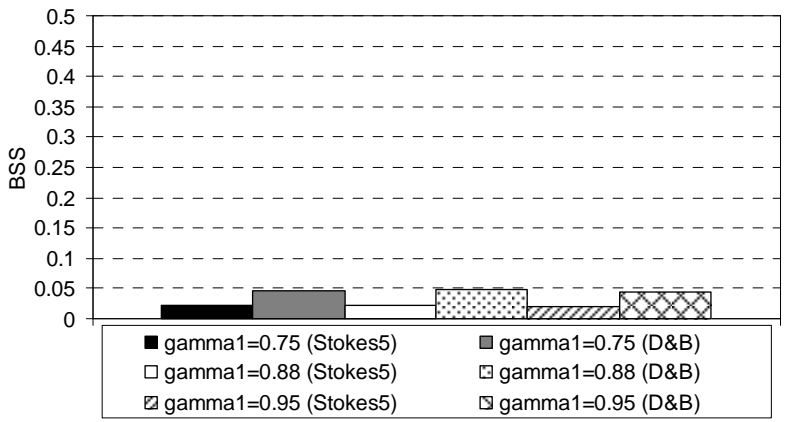

d)

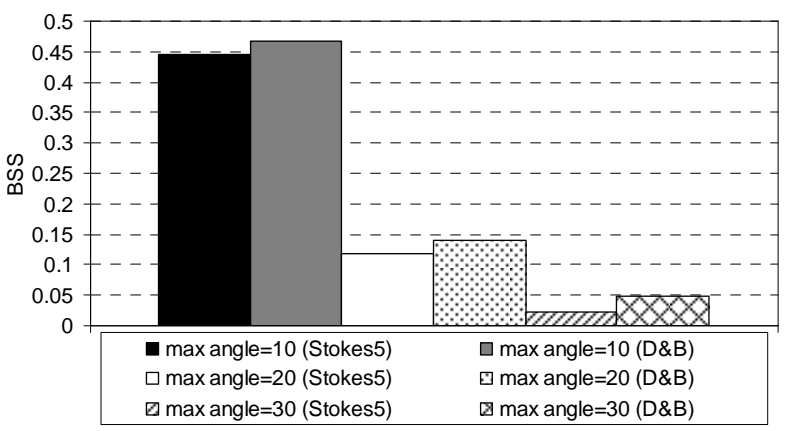

Figura 12 - Indicador de erro BSS para os testes de calibração do modelo Litprof (para as teorias de onda Stokes5 e D\&B). Parâmetros de calibração: a) $\gamma_{1}$, b) $\gamma_{2}$, c) $\alpha_{\text {scale }}$ e d) Maximum Angle of Bed Slope. 


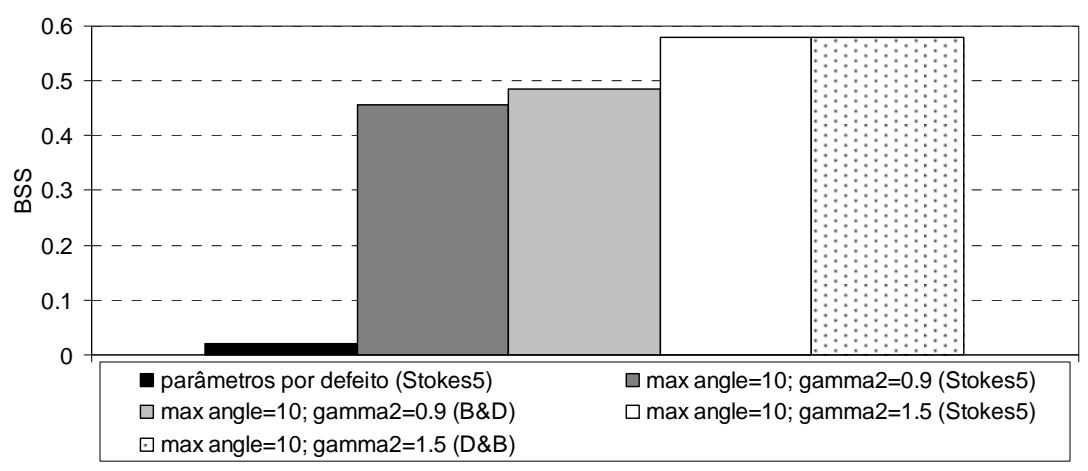

Figura 13 - Indicador de erro BSS para os testes de calibração do modelo Litprof (para as teorias de onda Stokes5 e D\&B) para o teste de combinação dos parâmetros de calibração $\gamma_{2}$ e Maximum Angle of Bed Slope.

\subsubsection{Comparação}

Compararam-se as simulações do modelo XBeach e Litprof (para a teoria de onda Stokes5, uma vez que a teoria de onda não se mostrou influente nos resultados) após calibração (e também de ambos os modelos com os parâmetros por defeito). Para cada um dos modelos considerou-se a aplicação com a qual se obteve o melhor desempenho do modelo, i.e., o modelo XBeach com o parâmetro Iws igual a 1 e o modelo Litprof com os parâmetros Maximum Angle of Bed Slope igual a $10^{\circ}$ e $\gamma_{2}$ igual a 1.5 .

Os resultados numéricos obtidos ao final de 6 horas (à escala laboratorial) mostram que ambos os modelos calibrados foram capazes de reproduzir erosão da duna, sendo o modelo XBeach que melhor reproduziu a configuração do perfil experimental (Figura 14). 0 modelo Litprof, apesar de ter reproduzido o recuo do topo da duna correctamente (Figuras 14 e 15c) e ter simulado a formação de uma barra submersa na posição observada experimentalmente (Figura 14), simulou incorrectamente o volume de erosão (cerca de metade do observado) e o declive da duna. Consequentemente, o modelo gerou um avanço da duna ao nível do mar em vez de recuo (Figura 15b). Assim, em problemas de engenharia, em que para além de se pretender estimar com precisão o volume de areia extraído da face da duna também se pretende estar do lado da segurança, recomenda-se a aplicação do modelo XBeach calibrado.

O desempenho do modelo XBeach melhorou consideravelmente após calibração: não só a configuração do perfil é mais concordante com a configuração experimental, quer na face da duna quer na parte submersa do perfil (Figura 14), como também os indicadores de impacto e de erro assim o demonstram (Figuras 15a-c e 16). Salienta-se o resultado do indicador de erro BSS para o modelo XBeach calibrado que classifica o desempenho do modelo como excelente, conforme classificação da Tabela 1. 


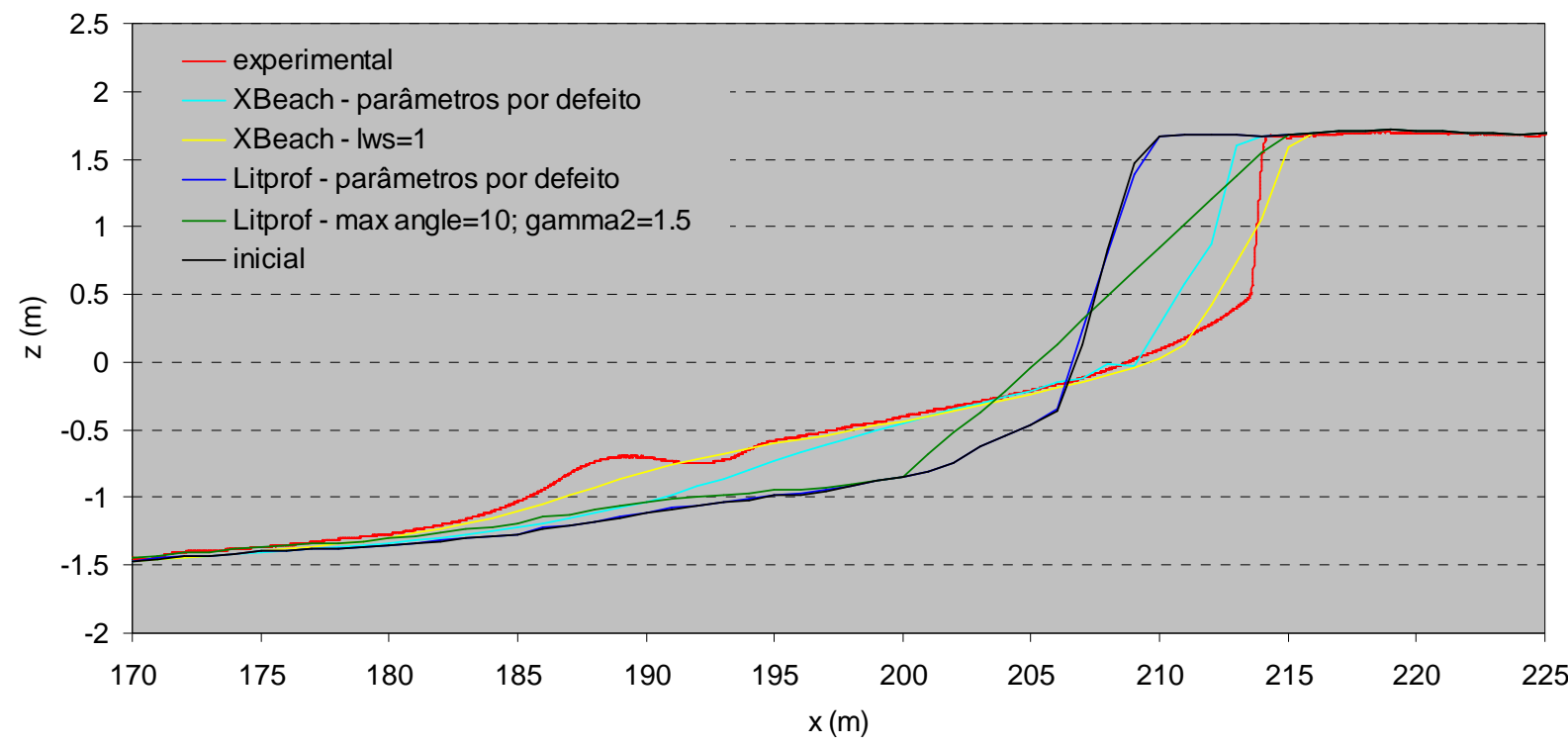

Figura 14 - Resultados numéricos dos modelos XBeach e Litprof (para a teoria de onda Stokes5) com parâmetros por defeitos e após calibração, à escala laboratorial. As linhas turquesa e amarela representam as previsões do XBeach com parâmetros por defeito e calibrado, respectivamente; as linhas azul e verde representam as previsões do Litprof (Stokes5) com parâmetros por defeito e calibrado, respectivamente; a linha vermelha representa o perfil experimental; e a linha preta representa o perfil inicial.

a)

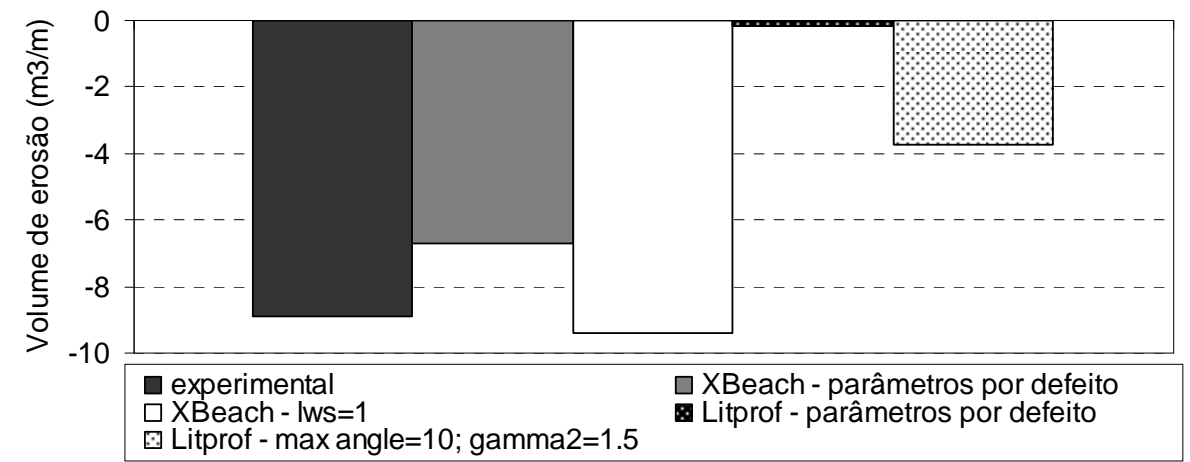

b)

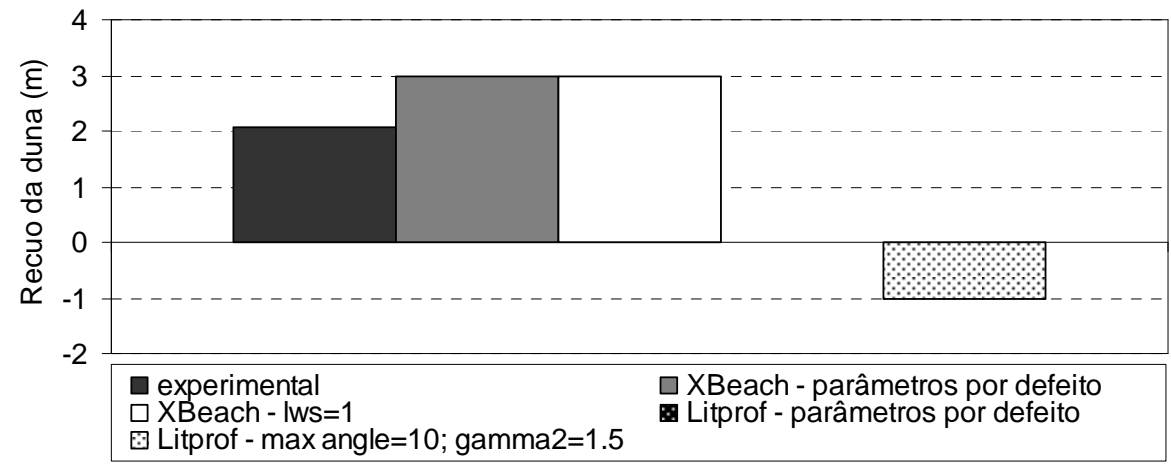


c)

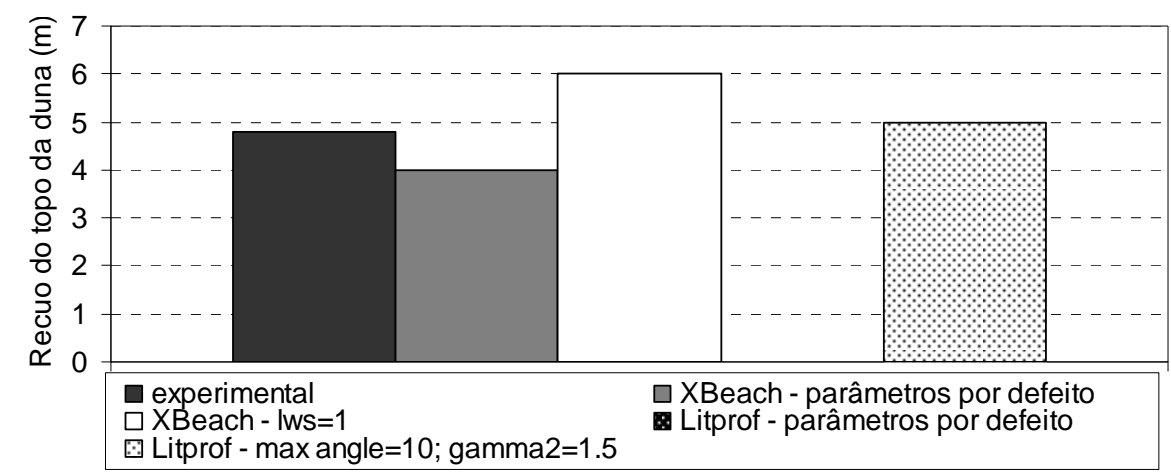

Figura 15 - Indicadores de impacto para os modelos XBeach e Litprof (para a teoria de onda Stokes5) com parâmetros por defeito e após calibração: a) Volume de erosão, b) Recuo da duna e c) Recuo do topo da duna.

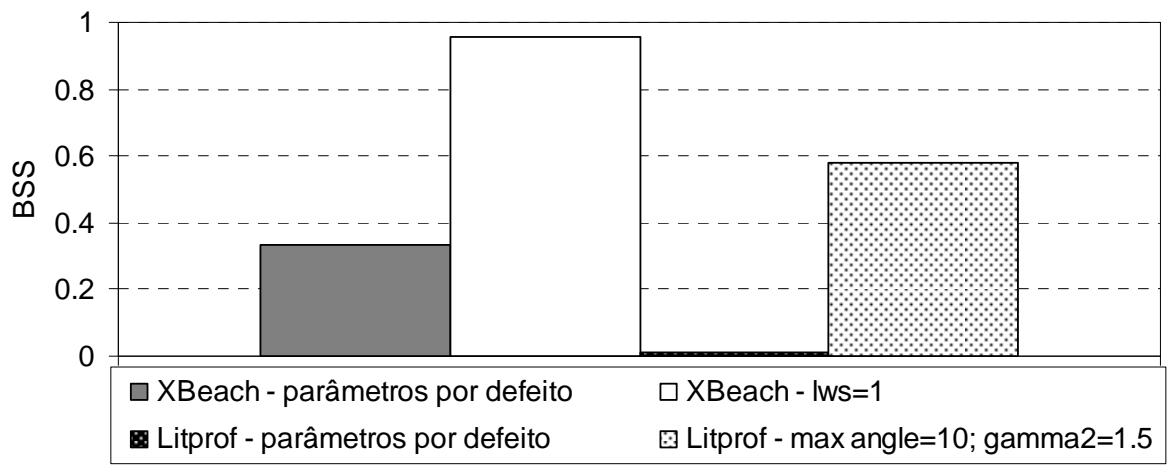

Figura 16 - Indicador de erro BSS para os modelos XBeach e Litprof (para a teoria de onda Stokes5) com parâmetros por defeito e após calibração. 


\section{Sumário, conclusões e trabalho futuro}

Testaram-se os modelos morfodinâmicos XBeach e Litprof na de erosão de dunas durante tempestades marítimas. $O$ caso de verificação tratou-se de um perfil de praia arenoso com uma duna bastante robusta testado em canal de grande escala de laboratório. Numa primeira fase testaram-se os modelos com os parâmetros por defeito (standard set of parameter settings). Numa segunda fase calibraram-se os modelos, ajustando os parâmetros de forma a melhorar o seu desempenho, i.e., a similaridade com os resultados observados. Em cada uma das fases compararam-se os resultados de ambos, sempre com base nos resultados observados durante a evolução do perfil experimental. Avaliou-se o desempenho dos modelos na previsão da evolução do perfil com base em indicadores de impacto (volume de erosão, recuo da duna e recuo do topo da duna) e no indicador de erro, BSS.

A aplicação do modelo XBeach com os parâmetros por defeito mostrou que o modelo simulou de forma razoável a acção erosiva das ondas na quase totalidade do perfil, sendo as maiores diferenças relativamente aos resultados experimentais verificadas no declive da duna, que se observou quase vertical durante a experiência laboratorial e o modelo reproduziu mais suave, e na barra submersa formada na extremidade da zona activa do perfil, que o modelo não reproduziu. 0 modelo reproduziu correctamente 0 recuo do topo da duna mas não o recuo observado ao nível da água. Consequentemente, o volume de erosão simulado foi de $75 \%$ do valor observado. Tal facto evidencia falta de realismo na formulação matemática do processo de avalanche. Relativamente à parte submersa do perfil, admite-se que o facto do modelo subestimar a extensão da zona de acumulação da areia transportada da face da duna se deve em grande parte ao facto do volume de erosão ser subestimado pelo modelo e não necessariamente a falta de realismo da formulação de transporte. Assim, numa aplicação de engenharia, em que importa não só a precisão como também estar do lado da segurança, recomenda-se precaução na aplicação do modelo XBeach com os parâmetros por defeito para previsão da erosão de dunas.

A aplicação do modelo Litprof com os parâmetros por defeito mostrou que o modelo não reproduz 0 processo de erosão da duna. Considera-se por isso que dos modelos Xbeach e Litprof aquele com melhor desempenho com os parâmetros por defeito é o modelo XBeach.

Discutiram-se, sugeriram-se e testaram-se doze parâmetros de calibração do modelo XBeach, que foram: beta, break, facsl, facua, gammax, hmin, hswitch, Iws, turb, wets/p dryslp e order. Fez-se variar cada um destes parâmetros de cada vez relativamente à situação default (com os parâmetros por defeito) e concluiu-se que os parâmetros mais influentes na evolução morfológica para este caso de estudo foram beta, break, facua, gammax, hswitch, Iws e wets/p. Destes, os parâmetros Iws e wets/p foram aqueles que conferiram ao perfil final uma geometria mais próxima da configuração observada. Os resultados obtidos para o indicador de erro BSS evidenciam que o melhor desempenho foi obtido com alteração do parâmetro Iws de 0 (por defeito) para 1 e que o segundo melhor desempenho foi obtido com a alteração do parâmetro wets/p de 0.3 (por defeito) para 0.15 , sendo a ambos atribuída a classificação de excelente. Uma vez que a alteração morfológica alcançada com a modificação do parâmetro Iws permitiu melhorar a previsão das duas características fundamentais sob o ponto de vista da engenharia que são o recuo do topo da duna e o limite da extensão da zona activa (onde se observou a formação da barra submersa durante a experiência), considera-se que este parâmetro é de grande relevância na simulação da evolução da erosão de dunas com o modelo XBeach.

Testaram-se quatro parâmetros de calibração do modelo Litprof para cada teoria de onda. Eles foram: os parâmetro de rebentação $\gamma_{1}$ e $\gamma_{2}$, o parâmetro de escala $\alpha_{\text {scale }}$ e o máximo ângulo de fundo submerso (Maximum Angle of Bed Slope). Fez-se variar cada um destes parâmetros de cada vez relativamente à situação default (com os parâmetros por defeito) e concluiu-se que os três primeiros parâmetros não afectam a evolução do perfil mas apenas o parâmetro Maximum Angle of Bed Slope é eficaz na calibração do modelo, pois causa erosão da duna. Concluiu-se que a falta de similaridade entre os 
resultados numéricos obtidos com o modelo Litprof e os resultados experimentais deve-se ao facto do modelo não abordar correctamente o processo de avalanche em zona seca nem considerar a acção de ondas longas. Concluiu-se que apenas limitando o máximo declive de fundo, e desta forma acelerando 0 processo de instabilidade do fundo, é possível causar erosão na base da duna com o modelo Litprof. Com base nesta conclusão, testou-se o modelo à variação dos parâmetros $\gamma_{2}$ e Maximum Angle of Bed Slope combinados, na expectativa de que a alteração do perfil alcançada através da deposição da areia erodida da face da duna (à custa da redução do Maximum Angle of Bed Slope) causasse um aumento do transporte para maiores profundidades no caso de se fazer variar o parâmetro $\gamma_{2}$ (máxima razão entre a altura de onda e a profundidade, $\mathrm{H} / \mathrm{h}$ ). Foi com esta combinação de parâmetros de calibração que se obteve o melhor desempenho do modelo Litprof. No seu melhor desempenho, classificado como razoável através do indicador de erro BSS, o modelo Litprof reproduziu o recuo do topo da duna correctamente, simulou a formação de uma barra submersa na posição observada experimentalmente, simulou incorrectamente 0 volume de erosão (cerca de metade do observado) e 0 declive da duna, e consequentemente gerou um avanço da duna ao nível do mar em vez de recuo. Por este motivo, recomenda-se muita precaução na aplicação do modelo Litprof para previsão da erosão de dunas. Verificou-se também que a teoria de onda não foi relevante na evolução do perfil neste caso de estudo.

Da comparação dos modelos morfodinâmicos XBeach e Litprof nas duas fases, i.e., na fase de teste com os parâmetros por defeito e na fase de calibração, concluiu-se que foi o modelo Xbeach que apresentou o melhor desempenho neste caso de estudo. A execução deste estudo permitiu testar e ficar a conhecer a elevada capacidade do modelo XBeach e a razoável capacidade do modelo Litprof na previsão da erosão de dunas. Concluiu-se que o modelo XBeach tem um elevado potencial na avaliação e previsão da vulnerabilidade de dunas pois não só apresentou um excelente desempenho neste caso de estudo, como também, sendo um modelo aberto a futuro desenvolvimento por parte da comunidade científica, possibilita a alteração (introdução e/ou melhoria) do tratamento matemático dos processos físicos envolvidos na morfodinâmica costeira. Relativamente a este último potencial, acrescenta-se que este estudo permitiu deste já identificar o processo de avalanche como um processo cujo tratamento matemático deve ser melhorado para tornar as simulações do modelo mais realistas.

Lisboa, Laboratório Nacional de Engenharia Civil, I.P., Dezembro 2011.

VISTOS

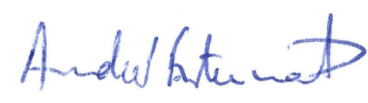

André Fortunato

Chefe do Núcleo de

Estuários e Zonas Costeiras

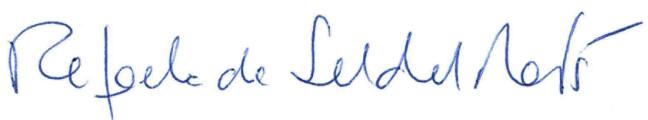

Rafaela de Saldanha Matos

Directora do Departamento de Hidráulica e Ambiente
AUTORIA

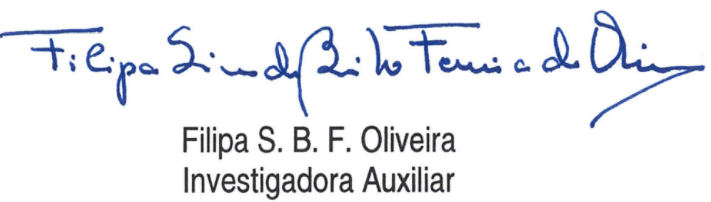

Filipa S. B. F. Oliveira

nvestigadora Auxiliar 


\section{Referências}

Battjes, J.A. and Stive, M.J.F., 1984. Calibration and verification of a dissipation model for random breaking waves, Coastal Eng. pp. 649-660.

Battjes, J.A., and Janssen, J.P.F.M., 1978. Energy Loss and Set-Up due to Breaking of Random Waves. Proc. of the 16th Int. Conf. on Coastal Eng. pp. 569-587, Hamburg.

Brandenburg, P.G.F., 2010. Scale dependency of dune erosion models. Performance assessment of the DUROS and XBeach models for various experiment scales. M.Sc. Thesis in Water Engineering \& Management, University of Twente, The Netherlands.

Dally, W.R. and Brown, C.A., 1995. A modeling investigation of the breaking wave roller with application to cross-shore currents. J. of Geophys. Researc, Vol. 100, No. C12, pp. 24.873-24.883.

Damgaard, J., Dodd, N., Hall, L., Chesher, T., 2002. Morphodynamic modelling of rip channel growth. Coastal Engineering, 45, 199-221.

DHI, 2008. Profile development. LITPROF user guide. Danish Hydraulic Institute.

Doering, J.C. and Bowen, A.J., 1995. Parametrization of orbital velocity asymmetries of shoaling and breaking waves using bispectral analysis. Coastal Engineering, Vol. 26, pp. 15-33.

Engelund, F. and Fredsøe, J., 1976. A sediment transport model for straight alluvial channels, Nordic Hydrology, 7, pp. 296-306.

Feddersen, F., Guza, R.T., Elgar, S., Herbers, T.C., 2000. Velocity moments in alongshore bottom shear stress parameterizations. Journal of Geophysical Research, 105, 8673-8688.

Fenton, J., 1985. A fifth-order Stokes theory for steady waves. J. Coastal, Port. Waterway and Ocean Eng., ASCE, Vol. 111, pp. 216-234.

Fredsøe, J. and Deigaard, R., 1992. Mechanics of Coastal Sediment Transport. Advanced Series on Ocean Engineering, Vol. 3, World Scientific.

Guza, R.T., Thornton, E.B., 1982. Swash oscillations on a natural beach. Journal of Geophysical Research 86 (C5), 4133-4137.

Larson, M. and Kraus, N.C., 1989. SBEACH: Numerical model for simulating storm-induced change. Report 1. Empirical formulation and model development. Technical report CERC-89-9, US Army Engineer Waterways Experiment Station, Coastal Engineering Research Center, Vicksburg, MS.

Nairn, R.B., Roelvink, J.A., Southgate, H.N., 1990. Transition zone width and implications for modelling surfzone hydrodynamics. 22nd ICCE, Delft, The Netherlands, pp. 68-81.

Oliveira, F.S.B.F., 2001. Transporte Litoral perpendicular à costa. Relatório 1 - Modelação Matemática da Hidrodinâmica e Transporte de Sedimentos na Zona Costeira. Laboratório Nacional de Engenharia Civil, Lisboa, Portugal.

Oliveira, F.S.B.F., 2011. Avaliação do modelo de erosão de praias e dunas XBeach. Relatório 326/2011 NEC, Laboratório Nacional de Engenharia Civil, Lisboa, Portugal.

Phillips, O.M., 1977. The dynamics of the upper ocen. 2nd ed. Cambridge University Press, New York, $336 \mathrm{pp}$.

Raubenheimer, B., Guza, R.T., 1996. Observations and predictions of run-up. Journal of Geophysical Research, 101 (C10) 25575-25587. 
Reniers, A.J.H.M., Roelvink, J.A., Thornton, E.B., 2004a. Morphodynamic modelling of na embayed beach under wave group forcing. Journal of Geophysical Research, 109, C01030. doi: 10.1029/202JC001586.

Reniers, A.J.H.M., Thornton, E.B., Stanton, T., Roelvink, J.A., 2004b. Vertical flow structure during Sandy Duck: observations and modelling. Coastal Engineering, 51 (3), 237-260.

Roelvink, J.A., 1993. Dissipation in random wave groups incident on a beach. Coastal Engineering 19, 127-150.

Roelvink, J.A., van Kessel, T., Alfageme, S., Canizares, R., 2003. Modelling of barrier island response to storms. Proc. Coastal Sediments '03, Clearwater, Florida.

Roelvink, D., Reniers, A., Dongeren, A., Vries, J.T., McCall, R. and Lescinski, J., 2009. Modelling storm impacts on beaches, dunes and barrier islands. Coastal Engineering, 56, 1133-1152.

Roelvink, D., Reniers, A., Dongeren, A., Vries, J.T., Lescinski, J. and McCall, R., 2010. XBeach model description and manual. Report. Unesco-IHE Institute for Water Education, Deltares and Delft University of Technology.

Ruessink, B.G., Miles, J.R., Feddersen, F., Guza, R.T., Elgar, S., 2001. Modeling the alongshore current $\mathrm{n}$ barred beaches. Journal of Geophysical Research, 106, 22451-22463.

Sallanger, A.H., 2000. Storm impact scale for barrier islands. Journal of Coastal Research, 16 (3), 890895.

Soulsby, R.L., Hamm, L., Klopman, G., Myrhaug, D., Simons, R.R., Thomas, G.P., 1993. Wave-current interaction within and outside the bottom boundary layer. Coastal Engineering, 21, 41-69.

Soulsby, R.L., 1997. Dynamics f Marine Sands. Thomas Telford, London.

Stive, M.J.F. and Vriend, H.J., 1994. Shear stresses and mean flow in shoaling and breaking waves. In: Edge, B.L. (Ed.) Proceedings of the 24th International Conference: American Society of Civil Engineering, Reston, Va, pp. 594-608.

Sutherland, J., Peet, A.H., Soulsby, R.L., 2004. Evaluating the performance of morphological models. Coastal Engineering, 51, pp. 917-939.

Svendsen, I.A., 1984. Wave heights and set-up in a surf zone. Coastal Engineering, 8, 303-329.

Tucker, M.J., 1954. Surfbeats: sea waves of 1 to 5 minutes' period. Proc. R. Soc. London, Ser. A 202, 565-573.

Van Rijn, L.C., Walstra, D.J.R., Grasmeijer, B., Sutherland, J., Pan, S., Sierra, J.P., 2003. The predictability of cross-shore bed evolution of sandy beaches at the time scale of storms and seasons using process-based profile models. Coastal Engineering, 47, pp. 295-327.

Van Thiel de Vries, J.S.M., van Gent, M.R.A., Walstra, D.J.R., Reniers, A.J.H.M., 2008. Analysis of dune erosion processes in large-scale flume experiments. Coastal Engineering, 55 (12).

Vellinga, P., 1986. Beach and dune erosion during storm surges. Ph.D. thesis Delft University of Tecnology.

Vousdoukas, M.I., Almeida, L.P. e Ferreira, Ó., 2011. Modelling storm-induced beach morphological change in a meso-tidal, reflective beach using XBeach. Journal of Coastal Research, SI 64, pp. 1916-1920.

WL | Delft Hydraulics, 2006. Dune erosion, Large-scale model tests and dune erosion prediction method. Report H4357, May 2006, Deft. 
Zyserman, J. e Fredsøe, J., 1994. Data analysis of bed concentration of suspended sediment. J. Hydr. Eng., ASCE, Vol 120, No 9. 
